OPEN ACCESS

Edited by:

Kai-Uwe Hinrichs,

University of Bremen, Germany

Reviewed by:

Arnaud Huguet, UMR 7619 Milieux Environnementaux,

Transferts et Interactions dans les hydrosystèmes et les Sols (METIS),

France

Sabine Kerstin Lengger, University of Plymouth,

United Kingdom

Kevin W. Becker,

Woods Hole Oceanographic

Institution, United States

${ }^{*}$ Correspondence:

Jayne E. Rattray

jayne.rattray@ucalgary.ca

Rienk H. Smittenberg

rienk.smittenberg@geo.su.se

${ }^{\dagger}$ Present address: Jayne E. Rattray, Department of Biological Sciences, University of Calgary, Calgary, $A B$,

Canada

Specialty section:

This article was submitted to Marine Biogeochemistry,

a section of the journal

Frontiers in Marine Science

Received: 01 March 2020

Accepted: 24 August 2020

Published: 18 September 2020

Citation:

Rattray JE and Smittenberg RH (2020) Separation of Branched

and Isoprenoid Glycerol Dialkyl Glycerol Tetraether (GDGT) Isomers in Peat Soils and Marine Sediments Using Reverse Phase Chromatography.

Front. Mar. Sci. 7:539601. doi: 10.3389/fmars.2020.539601

\section{Separation of Branched and} Isoprenoid Glycerol Dialkyl Glycerol Tetraether (GDGT) Isomers in Peat Soils and Marine Sediments Using Reverse Phase Chromatography

\author{
Jayne E. Rattray ${ }^{1 * t}$ and Rienk H. Smittenberg* \\ Department of Geological Sciences, Stockholm University, Stockholm, Sweden
}

Over the last decade, glycerol dialkyl glycerol tetraethers (GDGTs) have become one of the most investigated lipid classes in marine and terrestrial organic geochemical research. GDGTs are microbial membrane core lipids biosynthesized as multiple homolog series of isoprenoid or methyl-branched isomers [isoprenoid glycerol dialkyl glycerol tetraethers (isoGDGTs) and Branched GDGTs (brGDGTs), respectively], whose relative abundance depend on a range of environmental parameters, including temperature. This has led to the development of GDGT-based temperature proxies. A key aspect in the analysis of GDGTs and the further development of their use as environmental proxies is good chromatographic separation of the full range of structural and stereo-isomers, with potential for discovery of novel GDGT variants. Several HPLC methods have been developed to this extent, but partial co-elution of GDGTs remains an issue despite long run times. In this study, we investigate the effects of different types of reverse phase (RP) chromatography on the separation of GDGT isomers. We found that the use of a Kinetex C18-XB column gives good separation of isoGDGT isomers in comparison to the recently developed double column HILIC analysis operated in normal phase (NP) and has a shorter run time. In marine samples, the regularly reported isoprenoid GDGTs separated in a similar way as in NP, however an earlier eluting group was observed to elute with the crenarchaeol isomer used in the TEX proxy. In a Swedish peat bog sample, a large range of isoGDGT isomers were observed. We observed a range of brGDGT isomers in several samples often with near baseline separation. Exact identification of all these isomers remained elusive, due to the different mechanism of separation in RP, and the complexity of the brGDGT family. The C18-XB method is rapid and versatile and can be set up on either low-pressure HPLC systems (max 400 bar) with a sample run time of 25 min for brGDGTs and 45 min to include isoGDGTs. On UHPLC-MS systems (>600 bar) the sample run time is reduced to 15 min. Most importantly, the C18-XB method presented here gives unusual separation of both isoprenoid and brGDGTs and could be a useful tool for the further elucidation of the biological sources and environmental factors that play a role in the production of different GDGT isomers.

Keywords: tetraethers, HPLC-MS, isomer resolution, reverse phase, GDGT 


\section{INTRODUCTION}

Archaea, and more specifically Thaumarchaeota, are an abundant and diverse group of prokaryotes, inhabiting a range of marine, freshwater, terrestrial, and extreme environments (BrochierArmanet et al., 2012; Könneke et al., 2014). They have a deeply branching phylogeny emanating from ancient hot environments (de la Torre et al., 2008) and have evolved to play a major role in oceanic $\mathrm{CO}_{2}$ fixation and nitrogen cycling (Könneke et al., 2014; Tolar et al., 2016). Thaumarchaeal cell membranes are predominantly comprised of isoprenoid glycerol dialkyl glycerol tetraether (isoGDGT, Figure 1A) lipids which are biosynthetically regulated in response to environmental parameters like temperature, buffering capacity (Elling et al., 2017) and the core lipids are typically recalcitrant after cell death (Kuypers et al., 2001). The relationship between a ratio of sedimentary isoGDGTs and sea surface temperature is described in the $\mathrm{TEX}_{86}$ paleotemperature proxy (Schouten et al., 2002). Global calibration of the $\mathrm{TEX}_{86}$ ratio in marine core top sediments performed over the temperature range -2 to $30^{\circ} \mathrm{C}$ indicate that the relationship between the $\mathrm{TEX}_{86}$ ratio and temperature is a global phenomenon (Kim et al., 2008). In marine sediment cores $\mathrm{TEX}_{86}$ temperatures have been calculated as far back as the early Jurassic $(\sim 194 \mathrm{Ma})$, making the TEX $_{86}$ an important temperature proxy for understanding ocean warming and global climate change over extended geological time scales (Robinson et al., 2016). However, exceptions to the $\mathrm{TEX}_{86}$ temperature response have been found in sediments supporting the anaerobic oxidation of methane (Schouten et al., 2002; Zhang Y. G. et al., 2016) and hot-spring environments (Pearson et al., 2004; Zhang et al., 2006; Schouten et al., 2007). These are not only related to different groups of archaea being metabolically active, but also to the fact that many different structural and stereo-isomers exist. Recently, progress been made regarding the presence and relative abundance of isoGDGT regio-isomers, i.e., the parallel or antiparallel glycerol configurations (Becker et al., 2013; Liu et al., 2018), in part using selective sn2 ether cleavage after fraction collection of the co-eluting isomers (Liu et al., 2019). Also, the cyclopentane moiety adjacent to the cyclohexane ring in crenarchaeol was found to exhibit the unusual cis stereochemistry in contrast to the regular trans stereochemistry (Sinninghe Damsté et al., 2018). Lastly, structural isomers of isoGDGTs now also include examples with cyclohexane rings (so-called S-GDGTs) and with double bonds instead of rings (Liu et al., 2016). The structural and stereochemical variations found in glycerol dialkyl glycerol tetraethers (GDGTs) affect their packing as membrane lipids, which provide biophysical explanation for their variety.

Branched GDGTs (brGDGTs) (Figure 1B) were originally attributed to a terrestrial source as they were hypothesized to be produced by an unknown group of soil bacteria (Weijers et al., 2009). Increasing evidence now shows brGDGTs are also produced in situ in aquatic systems (De Jonge et al., 2014a,b; Liu et al., 2014; Zhang Z. H. et al., 2016; Naafs et al., 2017). The distribution of brGDGTs in soils, peats and lacustrine sediments has been found to relate to mean annual air temperature and pH (Weijers et al., 2007; Tierney et al., 2012; Schoon et al., 2013), leading to the development of the terrestrial paleoclimate proxies based on the MBT and CBT ratios (Weijers et al., 2007; De Jonge et al., 2014a). Exactly how other environmental factors like alkalinity, salinity, and euxinity (presence of $\mathrm{H}_{2} \mathrm{~S}$ ) influence the distributions of both isoGDGTs and brGDGTs is yet to be properly understood and can only be investigated efficiently if GDGT isomers are resolved sufficiently by HPLCMS chromatography.

Glycerol dialkyl glycerol tetraethers have traditionally been analyzed using normal phase (NP) chromatography (Hopmans et al., 2004; Schouten et al., 2013b). The separation of individual isoprenoid GDGTs occurs in the order of increasing cyclopentane rings and the NP chromatography is selective enough to allow separation of the crenarchaeol isomer $(\mathrm{m} / \mathrm{z}$ 1292) as a rider peak. More recently developed methods have successfully baseline separated the crenarchaeol isomer from crenarchaeol (Becker et al., 2013; Hopmans et al., 2016). The standard set of isoprenoid GDGTs elutes first in $\mathrm{NP}$ followed by $\mathrm{H}$-shaped and hydroxylated GDGTs $(\mathrm{OH}-$ GDGTs). In NP chromatography, brGDGTs elute after the isoprenoid GDGTs with the higher masses eluting first. Due to a lack of resolution it was difficult to discriminate between individual methyl-branched isomers. Recently, brGDGTs have been identified as 5-methyl, 6-methyl, and 7-methyl isomers using lengthy HPLC fractionation and subsequent isomer identification using Gas Chromatography/Mass Spectrometry analysis of the hydrocarbons formed after ether cleavage of the GDGTs (Liu et al., 2012b; De Jonge et al., 2013; Ding et al., 2016). Separation of brGDGTs using Cyano columns was then superceded using tandem silica hydrophobic interaction liquid (HILIC) chromatography columns run in NP mode (Hopmans et al., 2016). This method successfully separates the 5- and 6methyl-brGDGTs isomers but still has the disadvantage of a 90 min (plus 20 min re-equilibration) run time. The improved peak resolution of brGDGT isomers has further evolved the MBT and CBT proxies to include or exclude the 5- and 6methyl-branched isomers (De Jonge et al., 2014a; Naafs et al., 2017; Russell et al., 2018), but clearly more diversity exists as suggested by co-eluting 5/6 isomers (Liu et al., 2012b; Weber et al., 2015).

Other studies have successfully used RP chromatography columns (ACE3 C18, Agilent Eclipse XDB-C18, Nucleodur C18 ISIS, Waters Acquity UPLC BEH C18, Waters XBridge C18) for separating GDGTs (Wörmer et al., 2013; Zhu et al., 2013, 2014; Liu et al., 2016, 2018, 2019). The wide range of phases available for reverse phase (RP) chromatography gives the possibility to combine with ultra (U)-HPLC conditions (>600 bar), important for high resolution analysis and keeping the cost of analysis low. Different stationary phases potentially allow for a range of interaction mechanisms that can separate GDGT isomers, making this an interesting avenue for further method development in GDGT research. This paper builds on previous research into RP GDGT chromatography (Wörmer et al., 2013; Zhu et al., 2013; Liu et al., 2016, 2018) by investigating GDGT chromatography 
Rattray and Smittenberg

Enhanced Separation of GDGT Isomers

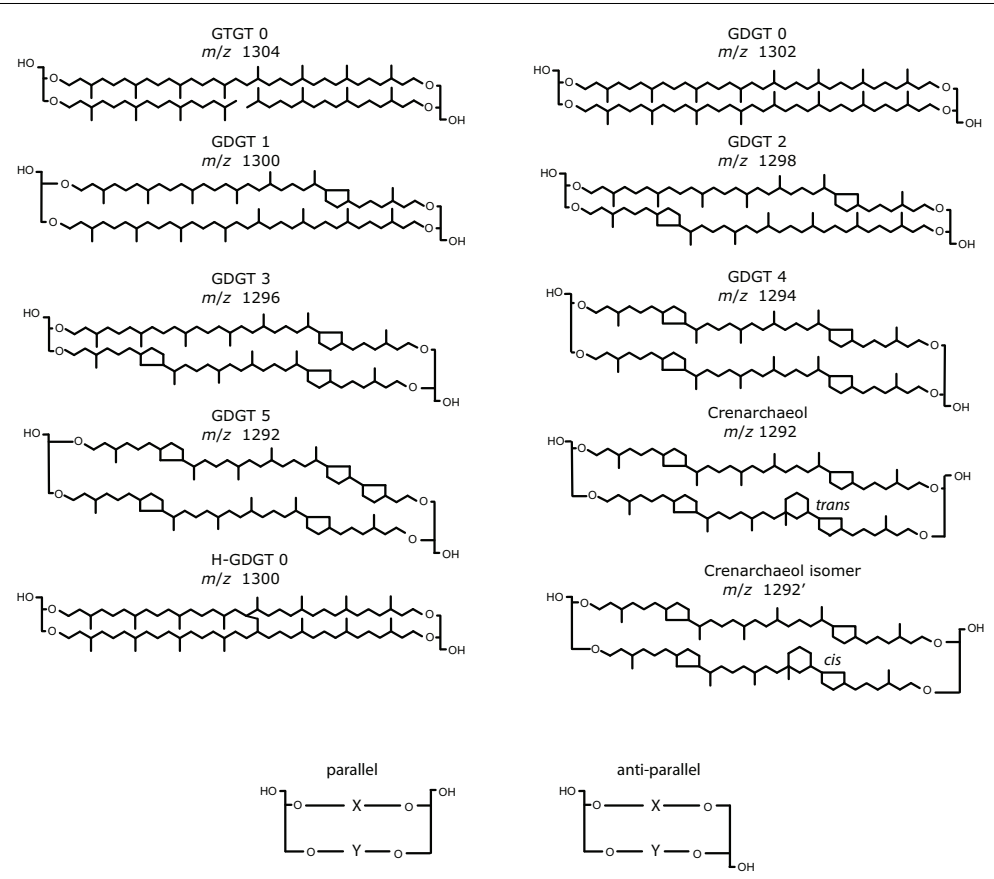

B
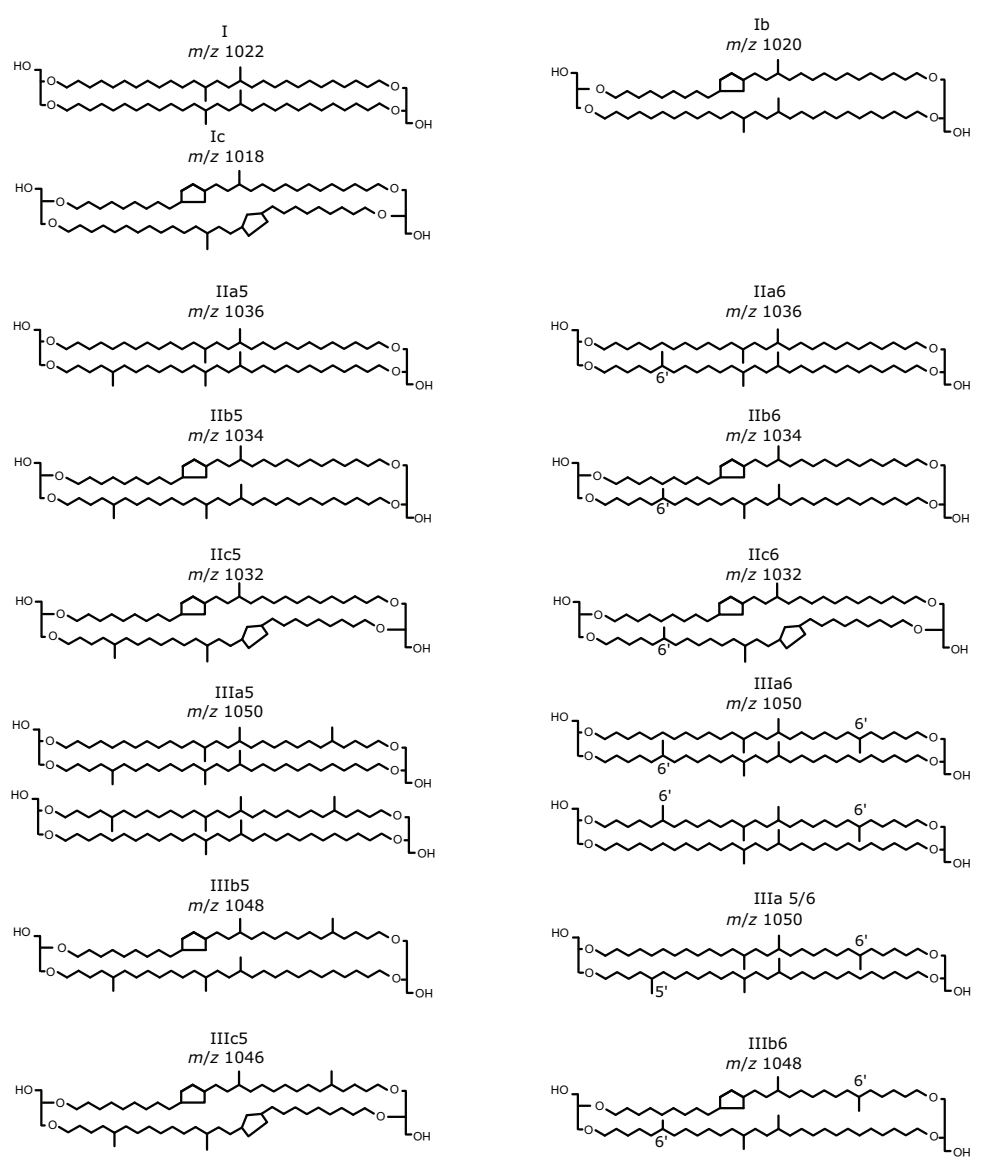

FIGURE 1 | Structures of (A) isoprenoid and (B) branched GDGTs including masses and common annotation found in the literature (Schouten et al., 2013b; De Jorge et al., 2014a). Note that this overview is not extensive and a large range of additional isomers are not shown (Lit et al., 2012b).

Frontiers in Marine Science | www.frontiersin.org

September 2020 | Volume 7 | Article 539601 
using four different RP core-shell particle column phases; C18-XB, PFP, C8, phenyl-hexyl. Subsequently the optimal RP method using the $\mathrm{C} 18-\mathrm{XB}$ column, hereafter termed $\mathrm{C} 18-\mathrm{XB}$ method, is compared with results from the conventional NP separation using a Cyano column (original GDGT method; Hopmans et al., 2004) and existing literature on RP to better understand GDGT isomer peak separation and distribution.

\section{MATERIALS AND METHODS}

\section{Sampling and Lipid Extraction}

In this study a total of 12 marine sediments (4 sites), 11 lacustrine sediments ( 2 sites), 22 peat bog soils ( 3 sites), and 1 sample of pre-purified GDGTs "Extract E" were used. Sample metadata are listed in Supplementary Table S1. Due to the often low quantities of sample extracts, not all samples were analyzed using every type of chromatography or column type, details of what samples are analyzed by the different methods are also found in Supplementary Table S1. All sediments were frozen and freeze dried after sampling and stored at $-20^{\circ} \mathrm{C}$ until extraction. For total lipid extraction, solid samples were ground prior to weighing and ultrasonically extracted $3 \times$ using methanol $(\mathrm{MeOH}), 3 \times$ dichloromethane $(\mathrm{DCM}) / \mathrm{MeOH}(1: 1$, $\mathrm{v}: \mathrm{v})$ and $3 \times \mathrm{DCM}$ or using $5 \times 2: 1 \mathrm{DCM}: \mathrm{MeOH}$. Extracts were combined to produce a total lipid extract which was subsequently dried using a vacuum concentrator or under a stream of $\mathrm{N}_{2}$. The Black Sea sample was extracted by Automated Solvent Extraction (ASE) as described by Birkholz et al. (2013). Extract $\mathrm{E}$ was provided as a pre-purified lipid extract as part of an international calibration study (Schouten et al., 2013a) and was stored at $-20^{\circ} \mathrm{C}$ until analysis. We also tested a British peat and marine extract (Figures 2, 3 and Supplementary Table S1) provided by David Naafs from the University of Bristol (Naafs et al., 2018). Lastly, we analyzed a sample from the lake sediment of a soda lake in central Myanmar (Taum Pyauk), which was extracted using ultrasonication as described above.

For NP analysis the dried lipid extract was reconstituted in 99:1 v/v Hexane:propan-2-ol and placed in an ultrasonic bath for $10 \mathrm{~min}$ to ensure proper mixing. The extract was then filtered using a $0.45 \mu \mathrm{m}, 4 \mathrm{~mm}$ diameter PFTE syringe filter. For RP analysis samples were re-dissolved in 9:1 MeOH: DCM (Zhu et al., 2013). Specifically, DCM was added first and vortexed to ensure lipids were brought into solution then $\mathrm{MeOH}$ was added. The samples were placed in an ultrasonic bath for $10 \mathrm{~min}$ before filtering through $0.45 \mu \mathrm{m}, 13 \mathrm{~mm}$ diameter PFTE syringe filters prior to analysis. We tested using ethyl acetate as a cheaper and lower toxicity alternative to DCM (Graeve and Janssen, 2009) by dissolving a Baltic Sea lipid extract aliquots into varying percentages of ethyl acetate and methanol (EtOAc:MeOH 99:1, 9:1, 8:2, and 6:4). The largest crenarchaeol peak area was obtained using either 99:1 or 6:4 EtOAc:MeOH $(\mathrm{v} / \mathrm{v})$ solution. However, repeat injections showed there was a large variation in peak area (range $8-15 \% \mathrm{RSD}, n=3$ ). In comparison, the average crenarchaeol peak area was less using the
9:1 MeOH:DCM solution but reproducibility was significantly higher (range $3-5 \%$ RSD, $n=3$ ), therefore we selected this solvent mixture.

\section{Analytical Instrumentation}

A Dionex Ultimate 3000RS quaternary pump stack including auto-sampler, column compartment and switching device were coupled via either an atmospheric pressure chemical ionization (APCI) ion source or a heated electrospray ionization interface (HESI used in ESI mode), to a Thermo Scientific TSQ quantum access MAX triple stage quadrupole max mass spectrometer. Both APCI and ESI (electrospray ionization) interfaces were tested and the APCI interface was selected because it gave repeatedly higher signal intensities and a lower background signal (Supplementary Figure S1).

The conditions used for APCI-MS were: discharge current $12 \mu \mathrm{A}$, vaporizer temperature $384^{\circ} \mathrm{C}$, sheath gas $0.4 \mathrm{l} / \mathrm{min}$, ion sweep gas pressure $0.6 \mathrm{l} / \mathrm{min}$, auxiliary gas pressure $1.5 \mathrm{l} / \mathrm{min}$ and capillary temperature $250^{\circ} \mathrm{C}$. Conditions of ESI-MS were: spray voltage $3 \mathrm{kV}$, vaporizer temperature $384^{\circ} \mathrm{C}$, sheath gas pressure $0.4 \mathrm{l} / \mathrm{min}$, ion sweep gas pressure $0.6 \mathrm{l} / \mathrm{min}$, auxiliary gas pressure $1.5 \mathrm{l} / \mathrm{min}$ and capillary temperature $229^{\circ} \mathrm{C}$. Branched and isoprenoid GDGTs were detected using positive ion spectra generated by scanning with selective ion monitoring over the following ranges: $\mathrm{m} / \mathrm{z}$ 741.2-744.8 (in $0.1 \mathrm{~s}$ ), $\mathrm{m} / \mathrm{z}$ 1016.5-1023.5 (in $0.2 \mathrm{~s}$ ), $\mathrm{m} / \mathrm{z}$ 1030.5-1037.5 (in $0.2 \mathrm{~s}$ ), $\mathrm{m} / \mathrm{z}$ 1044.5-1051.1 (in $0.2 \mathrm{~s}$ ), $\mathrm{m} / \mathrm{z}$ 1287.2-1304.8 (in $0.5 \mathrm{~s}$ ).

\section{Reverse Phase Chromatography}

An overview of the different analytical parameters of various NP and RP methods are given in Supplementary Table S2. To investigate the effect of different core-shell polymer phases on the isomer elution of GDGTs we selected columns from the same manufacturer (Phenomenex) to avoid any variation caused by the type of base silica used in HPLC column assembly. Four phase coatings were chosen for study: (1) A Kinetex C18-XB with iso-butyl side chains and TMS endcapping and a core shell silica solid support, $1.7 \mu \mathrm{m}, 100 \AA$, $150 \times 2.1 \mathrm{~mm}$; (2) A Kinetex C8, $1.7 \mu \mathrm{m}, 100 \AA$, $150 \times 2.1 \mathrm{~mm}$; (3) A Kinetex PFP (pentafluorophenyl), $1.7 \mu \mathrm{m}, 100 \AA, 150 \times 2.1 \mathrm{~mm}$; (4) A Kinetex phenyl-hexyl, $1.7 \mu \mathrm{m}, 100 \AA, 150 \times 2.1 \mathrm{~mm}$. The separation of GDGTs was achieved using mobile phase A: $\mathrm{MeOH}$ with $0.04 \%$ formic acid and mobile phase B: propan-2-ol with $0.04 \%$ formic acid (formic acid was used as a solvent additive for both ESI and APCI ionization methods) selected from previously described RP methods (Lanekoff and Karlsson, 2010; Zhu et al., 2013). The method used a flow rate of $0.2 \mathrm{ml} / \mathrm{min}$ and gave a typical pressure of around 300 bar at a column oven temperature of $45^{\circ} \mathrm{C}$. The initial composition of the mobile phase gradient was 60\%:40\% A:B was held for $1 \mathrm{~min}$ and then ramped to $50 \% \mathrm{~B}$ at $20 \mathrm{~min}$. This mix was held for $15 \mathrm{~min}$ then changed back to $40 \%$ $\mathrm{B}$ for column re-equilibration. The total run time was $45 \mathrm{~min}$ An injection volume of $10 \mu \mathrm{l}$ sample was used and samples were kept at ambient temperature to prevent coagulation of the sample which can cause higher back pressure if injected onto the column. We further created a UHPLC method by increasing the pump pressure and heating the column oven to $60^{\circ} \mathrm{C}$. A flow 
A Cyano (NP) Black Sea sediment extract

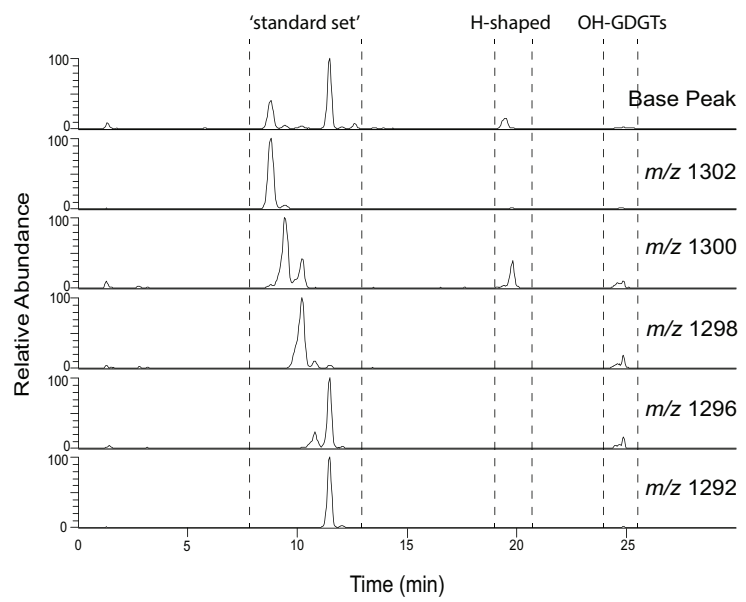

C Phenyl hexyl (RP) Black Sea sediment extract

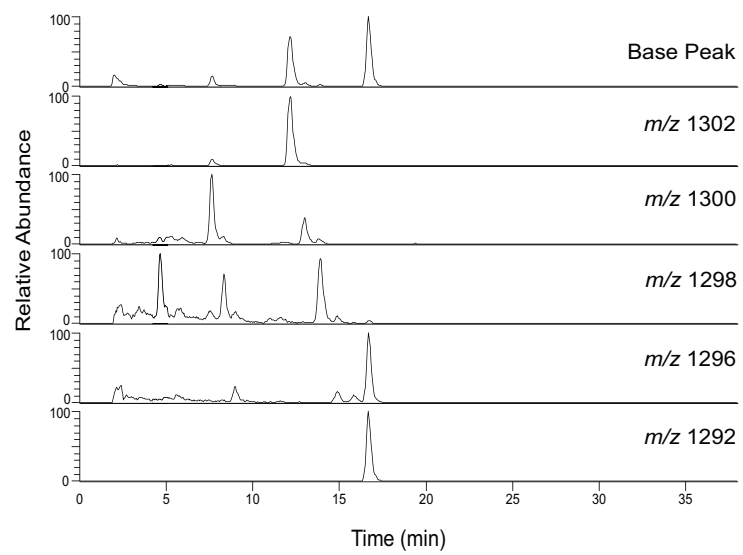

E

C18-XB (RP) Bristol Marine sediment extract

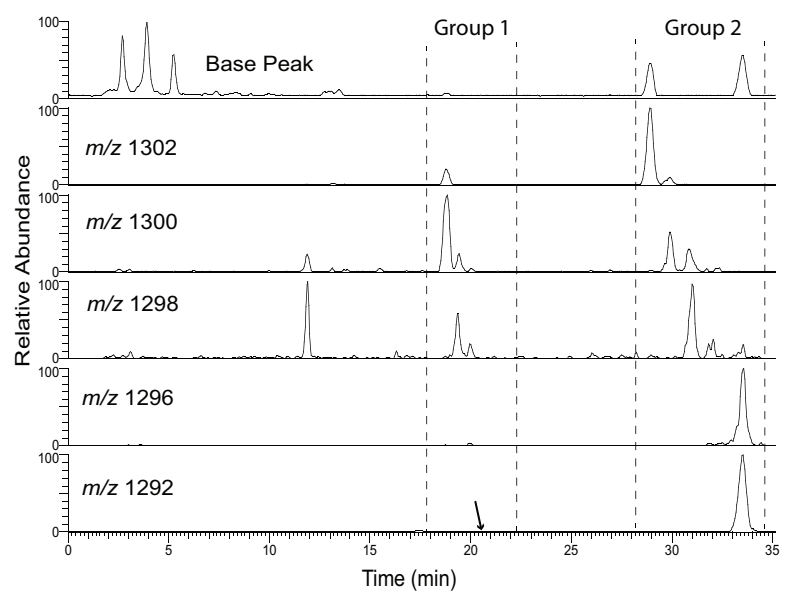

B C8 (RP) Black Sea sediment extract

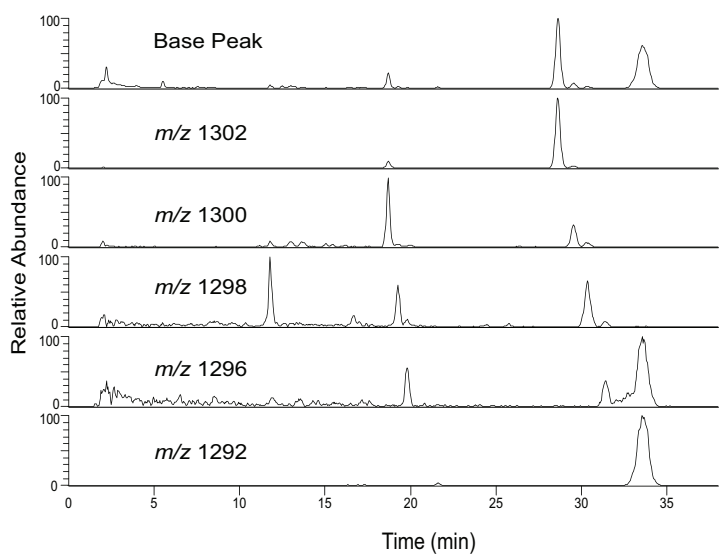

D C18-XB (RP) Black Sea sediment extract

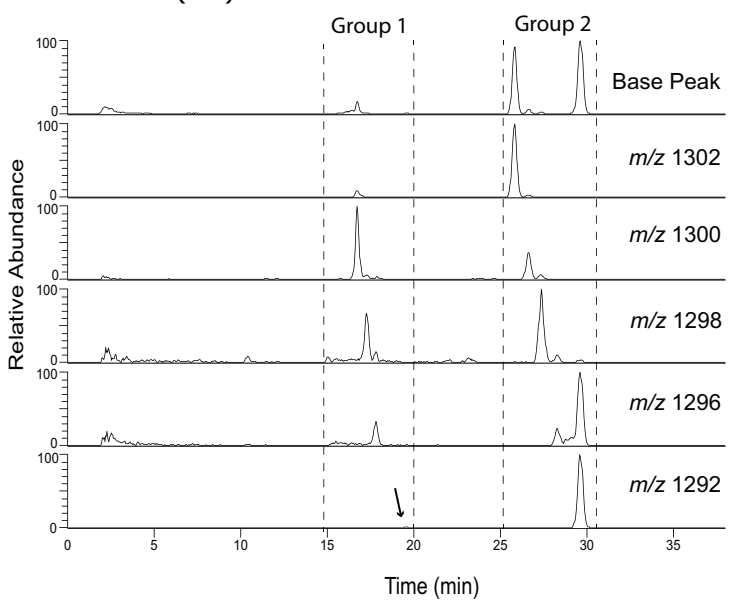

F HILIC (NP) Bristol Marine sediment extract

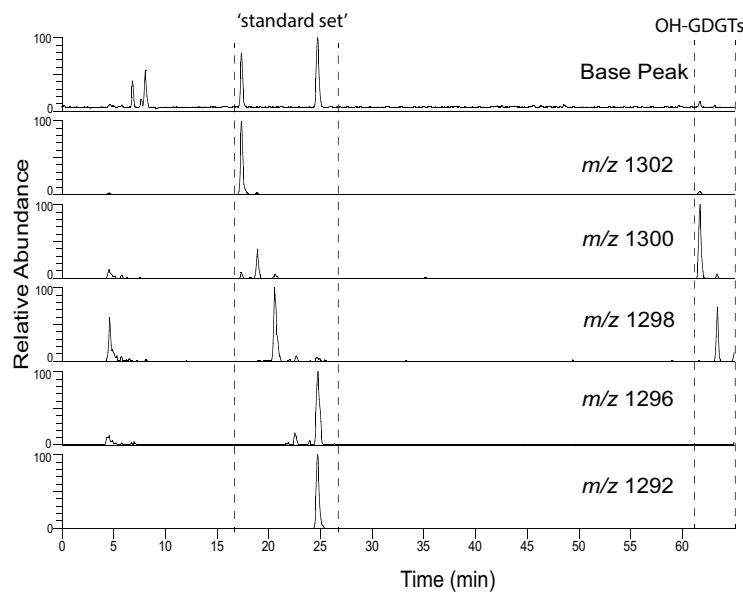

FIGURE 2 | Base peak and selected ion monitoring chromatogram of isoprenoid GDGTs from two marine sediment extracts. The Black Sea extract was analyzed using (A) Cyano column, NP; (B) C8, RP; (C) phenyl hexyl, RP; (D) C18-XB, RP columns. Due to a lack of sample material a Bristol marine sediment extract analyzed using (E) C18-XB and (F) HILIC is also shown. Indicated OH-GDGTs are identified using a combination of an RP fractionation experiment (described in section "Isoprenoid GDGTs in Marine Sediment"), RP and NP retention times found in the literature (see text). For RP, two clear groups can be identified. Note the small peak in the 1292 isomer is indicated by an arrow at 20 min in (D,E). Supplementary Figure S6A compares the chromatography of C18-XB and HILIC using the British peat extract. 
A Cyano (NP) Swedish peat bog extract

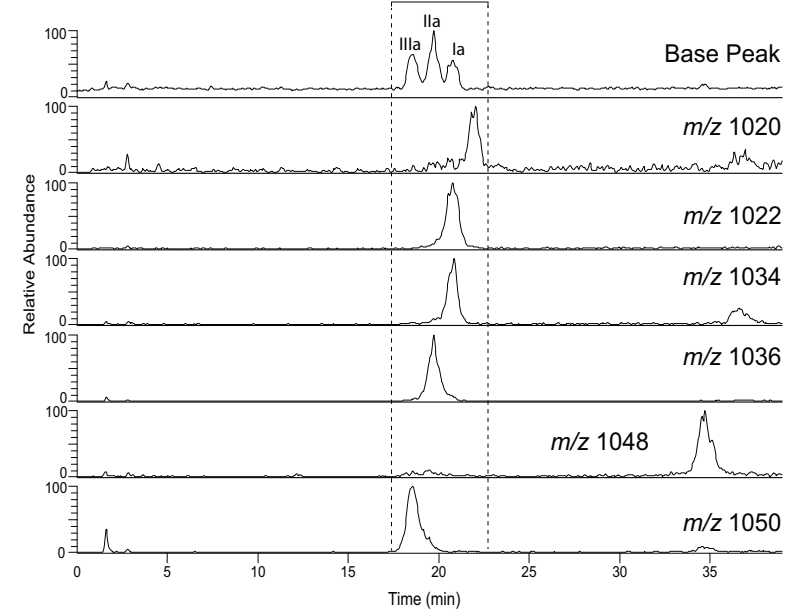

C Phenyl Hexyl (RP) Swedish peat bog extract

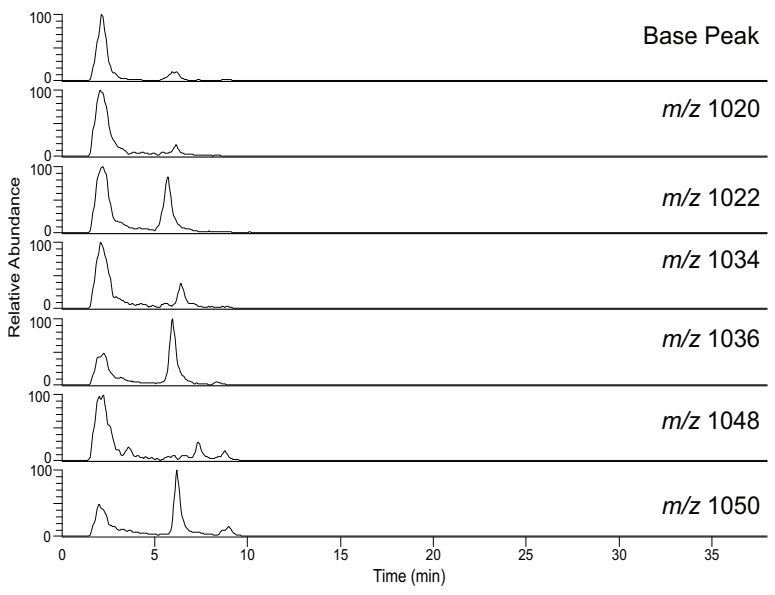

E $\quad$ 18-XB (RP) British peat extract

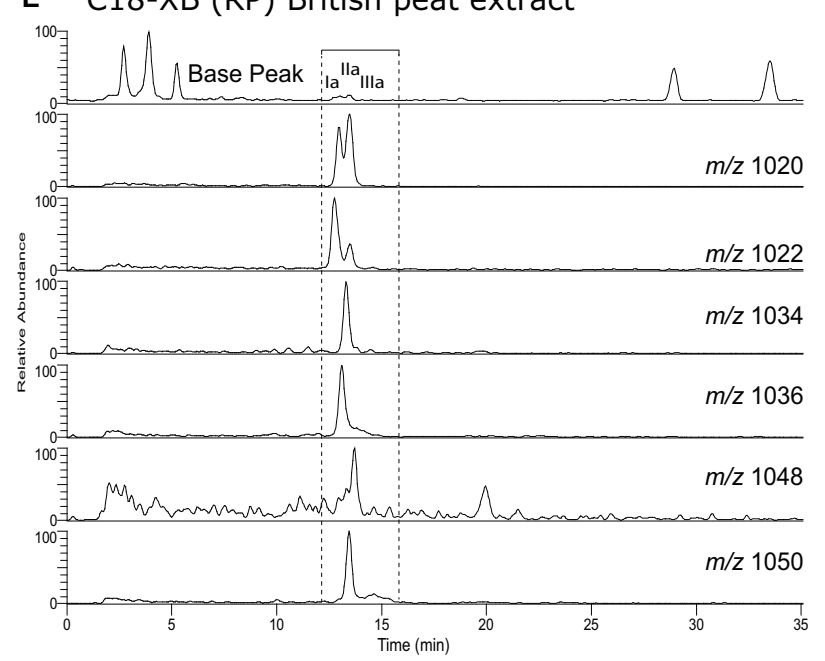

B $\quad$ C8 (RP) Swedish peat bog extract

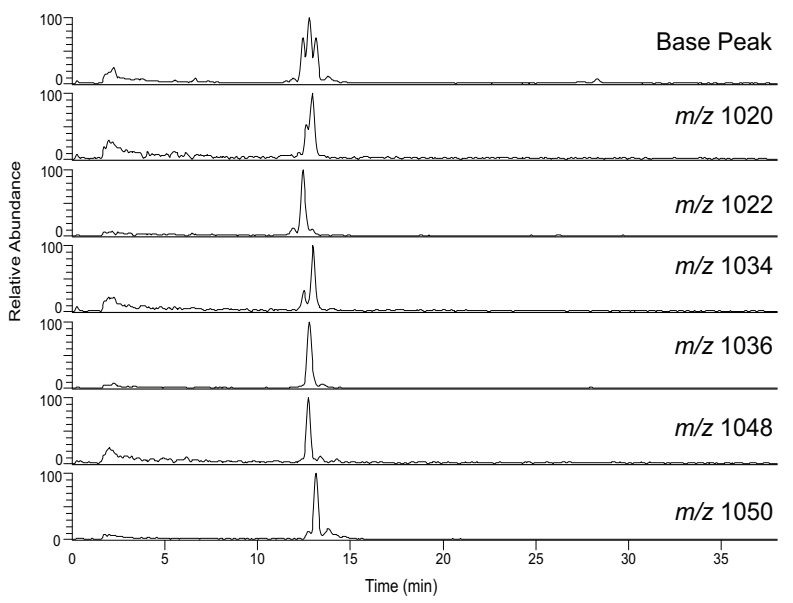

D $\quad$ C18-XB (RP) Swedish peat bog extract

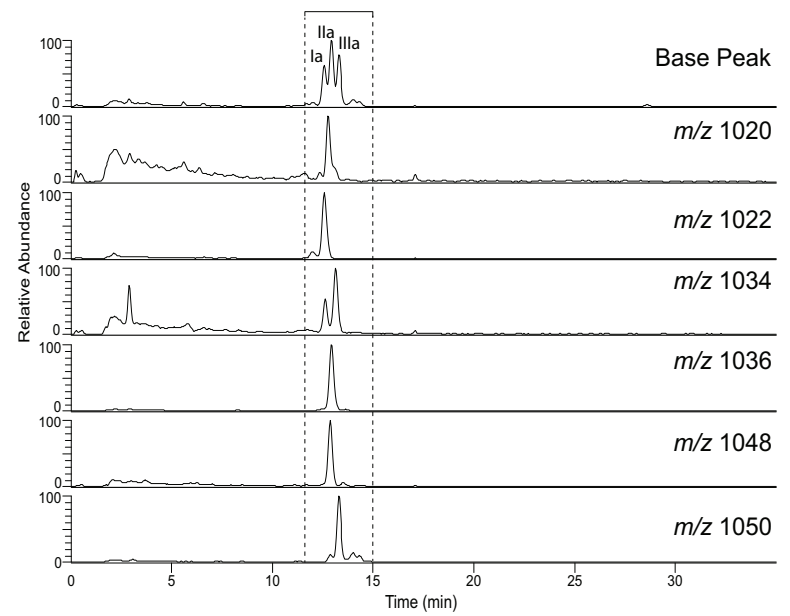

F $\quad$ HILIC (NP) British peat extract

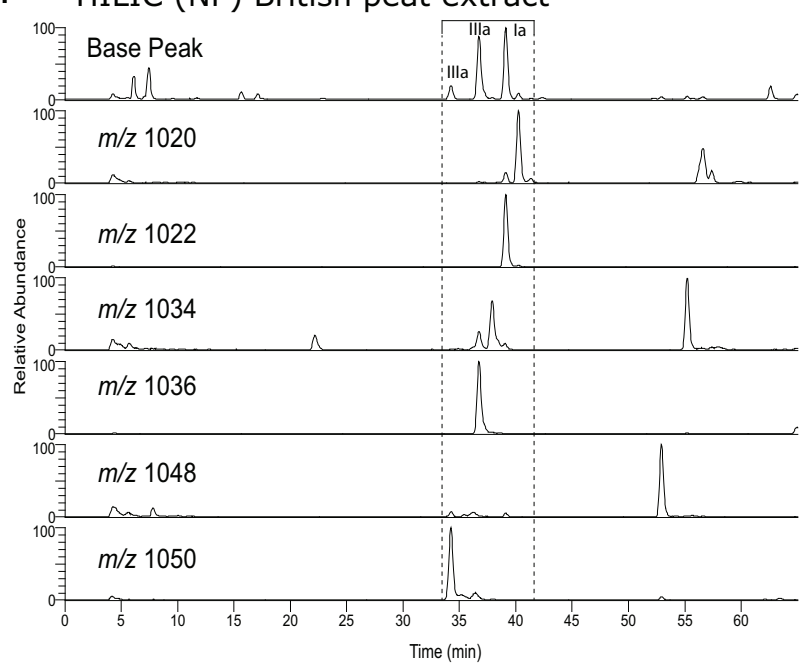

FIGURE 3 | Base peak and selected ion monitoring chromatogram of branched GDGTs from a two peat bog extracts. The Swedish peat extract was analyzed using (A) cyano, NP; (B) C8, RP; (C) phenyl hexyl, RP; (D) C18-XB, RP. A British peat extract analyzed was more recently analyzed using C18-XB and HILIC (E,F). Note the reverse order of the tetra (I), penta (II), and hexamethylated (III) GDGTs in NP and RP. Supplementary Figure S6B compares the chromatography of C18-XB and HILIC using the British peat extract. 
rate of $0.43 \mathrm{ml} / \mathrm{min}$ was used which gave a pressure of 600 bar. The initial composition of the mobile phase gradient was 60\%:40\% A:B, which was held for $1 \mathrm{~min}$ and then ramped to $50 \% \mathrm{~B}$ at $10 \mathrm{~min}$. This blend was held for $4 \mathrm{~min}$ and decreased back to $40 \% \mathrm{~B}$. The total run time was $15 \mathrm{~min}$. An injection volume of $2 \mu \mathrm{l}$ sample was used and samples were kept at ambient temperature during analysis. Lower injection volumes are necessary for UHPLC due to the small $(1.7 \mu \mathrm{m})$ silica pore size which requires a decreased loading capacity to reach optimal analyte peak shape and retention. Sharp peaks created in UHPLC methods mean a lower limit of detection and quantification can be achieved because small broad peaks are difficult to integrate and discriminate from the baseline.

\section{Normal Phase Chromatography}

Normal phase chromatography used a single Grace Prevail Cyano $3 \mu$ column $(150 \times 2.1 \mathrm{~mm}$; Grace Discovery Sciences, United States) similar to the method described by Hopmans et al. (2004). Gradient chromatography was hexane with 1\% propan-2ol (mobile phase A) followed by a linear gradient to $10 \%$ propan2-ol (mobile phase B) over $45 \mathrm{~min}$ using a flow rate of $1 \mathrm{ml} / \mathrm{min}$. After each analysis the column was cleaned by back-flushing hexane/propanol $(99: 1, \mathrm{v} / \mathrm{v})$ at $1 \mathrm{ml} / \mathrm{min}$ for $10 \mathrm{~min}$. The total run time was $60 \mathrm{~min}$ with an injection volume of $10 \mu \mathrm{L}$, samples were kept at ambient temperature during analysis. In addition, samples were run using a NP HILIC method as described in detail by Hopmans et al. (2016) except that our UHPLC pump was operated at a flow rate of $0.3 \mathrm{ml} / \mathrm{min}$ to give a faster gradient and higher backpressure. The system was monitored to ensure optimal peak resolution was achieved with each analysis.

\section{Fraction Collection}

To better understand the exact position and type of isoGDGT isomers on the C18-XB column we extracted large amounts of Baltic Sea sediment, for the brGDGT isomers we extracted Nong Thale Prong (NTP) lacustrine sediment and Swedish bog soil. Freeze dried ground soil or sediment $( \pm 60 \mathrm{~g})$ was extracted using $5 \times 2: 1 \mathrm{DCM}: \mathrm{MeOH}$. The total extract was separated over an $\mathrm{Al}_{2} \mathrm{O}_{3}$ column and the polar fraction eluted with 95:5 DCM:MeOH. The eluent was dried under a constant stream of nitrogen, re-dissolved in 9:1 MeOH:DCM (initially dissolving in DCM and vortexing then adding $\mathrm{MeOH}$ and vortexing), and filtered over a $0.45 \mu \mathrm{m}$ PTFE filter. The polar fraction was separated using a semi-preparative C18-XB column $(100 \AA$, $150 \times 2.1 \mathrm{~mm} 2.6 \mu \mathrm{m}$ ) fitted to a Dionex Ultimate 3000RS HPLC connected to a Dionex AFC-3000 automated fraction collector with splitting device. The flow rate was $0.2 \mathrm{ml} / \mathrm{min}$ with the following eluent gradient; $60 \%: 40 \% \mathrm{~A}: \mathrm{B}$ for $1 \mathrm{~min}$, linear gradient to $50 \% \mathrm{~B}$ at $20 \mathrm{~min}$. Hold for $15 \mathrm{~min}$ then $40 \% \mathrm{~B}$ for $9 \mathrm{~min}$ for column re-equilibration. Eluent $\mathrm{A}$ is $\mathrm{MeOH} / \mathrm{HCO}_{2} \mathrm{H}$ $(100 / 0.04 \mathrm{v} / \mathrm{v})$ and $\mathrm{B}$ is Propan-2-ol/ $\mathrm{HCO}_{2} \mathrm{H}(100 / 0.04 \mathrm{v} / \mathrm{v})$. Fractions were collected in 1 min intervals between 5 and $45 \mathrm{~min}$ and then re-analyzed for brGDGTs using the RP method. Selected isoGDGT fractions (collected $25-30 \mathrm{~min}$ ) were also analyzed using the NP method. Where possible, isomers were identified by direct injection of the fractions and performing MS/MS experiments. GDGT fragmentation patterns were compared with those published by Knappy et al. (2009), Liu et al. (2012b), De Jonge et al. (2014a), and Ding et al. (2016).

\section{RESULTS AND DISCUSSION}

\section{The Influence of Core-Shell Polymer Coatings on the Analysis of GDGTs}

Isomer retention and separation was investigated using repeat injection of GDGT lipids extracted from the Black Sea sediment. An environmental sample was used for column comparison due to the lack of commercially available standards for GDGT analysis and had the advantage of letting us understand environmental sample matrix effects at the start of method development. NP analysis using the cyano column (Figure 2A) eluted isoprenoid GDGTs in three separate series and the early eluting series contained peaks with the largest areas. Due to the more recent setup of the NP HILIC method and a lack of sample material, the HILIC method was tested at a later date using the Bristol marine standard extract which elutes the "standard set" of isoprenoid GDGT compounds between 17 and $26 \mathrm{~min}$ (Figure 2E and Supplementary Figure S6). Isoprenoid GDGT isomers in the early eluting "standard set" are used in $\mathrm{TEX}_{86}$ proxy calculation. The second eluting group in the NP method consists of $\mathrm{H}$-shaped GDGTs which have an approximately double retention time compared to the regular GDGTs (Naafs et al., 2018), and the third group OH-GDGTs.

On the $\mathrm{C} 8$ and $\mathrm{PH}$ columns (Figures 2B,C), three groups of GDGTs are observed (Figure 2), on the C18-XB (Figure 2D) two groups are seen, eluting between 17-22 (Group 1), and 2735 min (Group 2). The PFP column gave no retention of GDGTs so it was excluded from further study. On all three RP columns an undefined hump of non-retained compounds elutes at the start of the run (before $5 \mathrm{~min}$ ) and gives the largest peak area when using the $\mathrm{C} 8$ and $\mathrm{PH}$ column methods. After the analysis of different sediment and soils (Supplementary Table S1) it was found that non-retained compounds from the sample matrix appeared variable with sample type but elute prior to $2.5 \mathrm{~min}$ (in RP) and do not significantly affect the first group of GDGTs. Baseline separation of peaks from each other or undefined humps is essential for proper peak integration. In our experiments the best separation was observed using the $\mathrm{C} 8$ and $\mathrm{C} 18-\mathrm{XB}$ columns (Figures 3B,D) and the sharpest peaks were observed using the $\mathrm{C} 18-\mathrm{XB}$ column. On the $\mathrm{C} 18-\mathrm{XB}$ column retention time was tested for reproducibility. The standard reproducibility of the retention time of the largest and best resolved peak in the chromatogram $(m / z 1292, n=10)$ using repeat injections from different vials in the same sequence was $6 \mathrm{~s}$ and of repeat injections made in different runs (i.e., on different days) was $37 \mathrm{~s}$ $(m / z 1292, n=5)$. Comparing critical pairs calculated for the main GDGTs used in proxy calculation (Supplementary Table S3) shows the C18-XB method gives good separation of isoGDGT isomers in comparison to the recently developed double column HILIC analysis operated in NP.

Branched GDGT chromatography was investigated using a Swedish bog lipid extract. They were found to elute as a single series on all column types (Figure 3). Using NP 
(Figure 3A), brGDGTs elute later than the isoprenoid GDGTs and this is converse for the RP analysis (Figures 3B-D) as previously reported by Zhu et al. (2013) for RP chromatography. The tetramethylated (I) elute before the pentamethylated (II) and hexamethylated (III) homologs in RP, in contrast to the NP method where the order is III-II-I. Using a longer NP method gives the largest retention time difference between isomers I-III (De Jonge et al., 2013; Hopmans et al., 2016; Figure 3F). The PH column (Figure 3C) showed less retention of the brGDGTs and as a result was influenced by the hump of injection material. On both the $\mathrm{C} 8$ and $\mathrm{C} 18-\mathrm{XB}$ columns (Figures 3B,D) brGDGTs elute at similar retention times

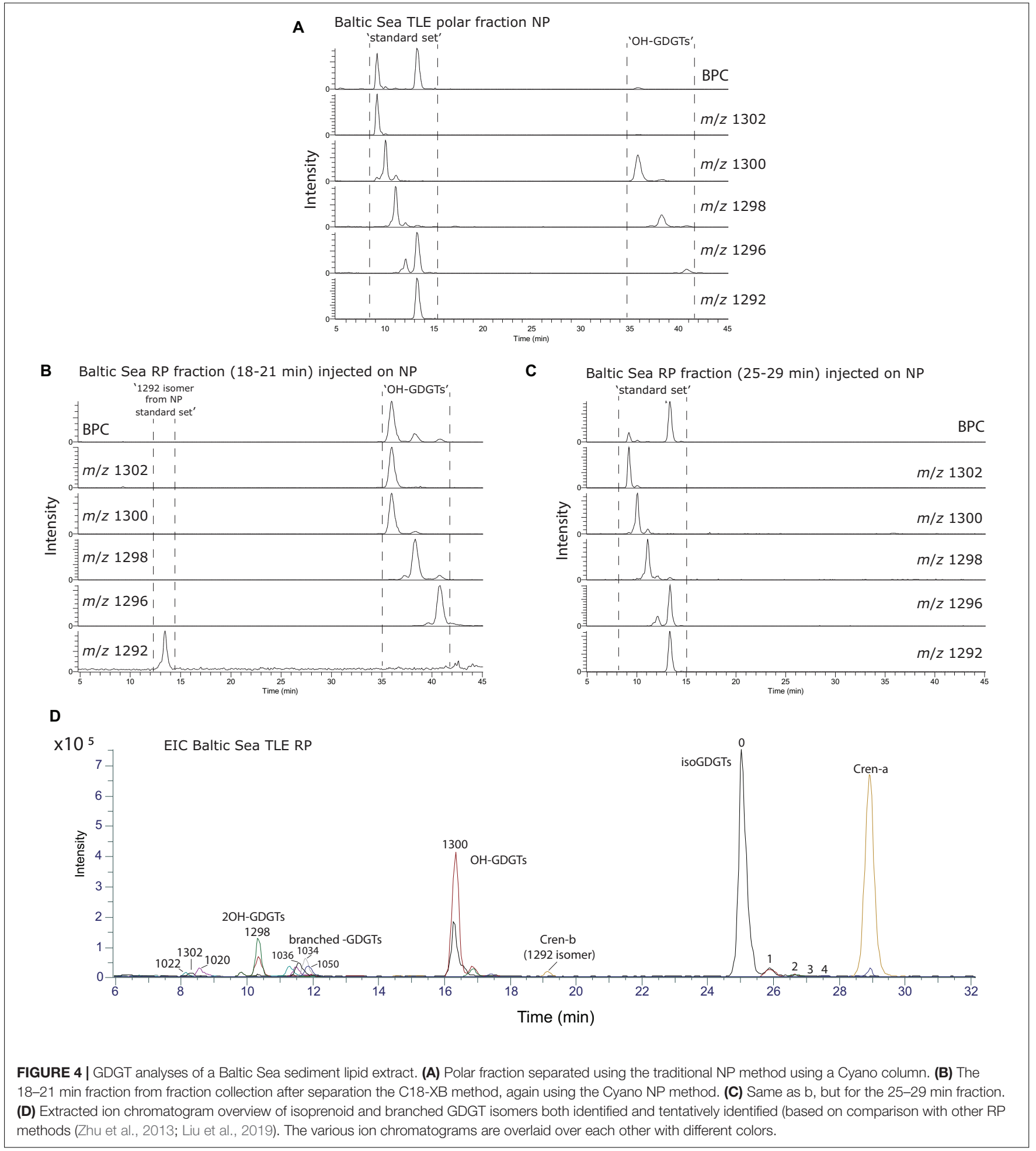




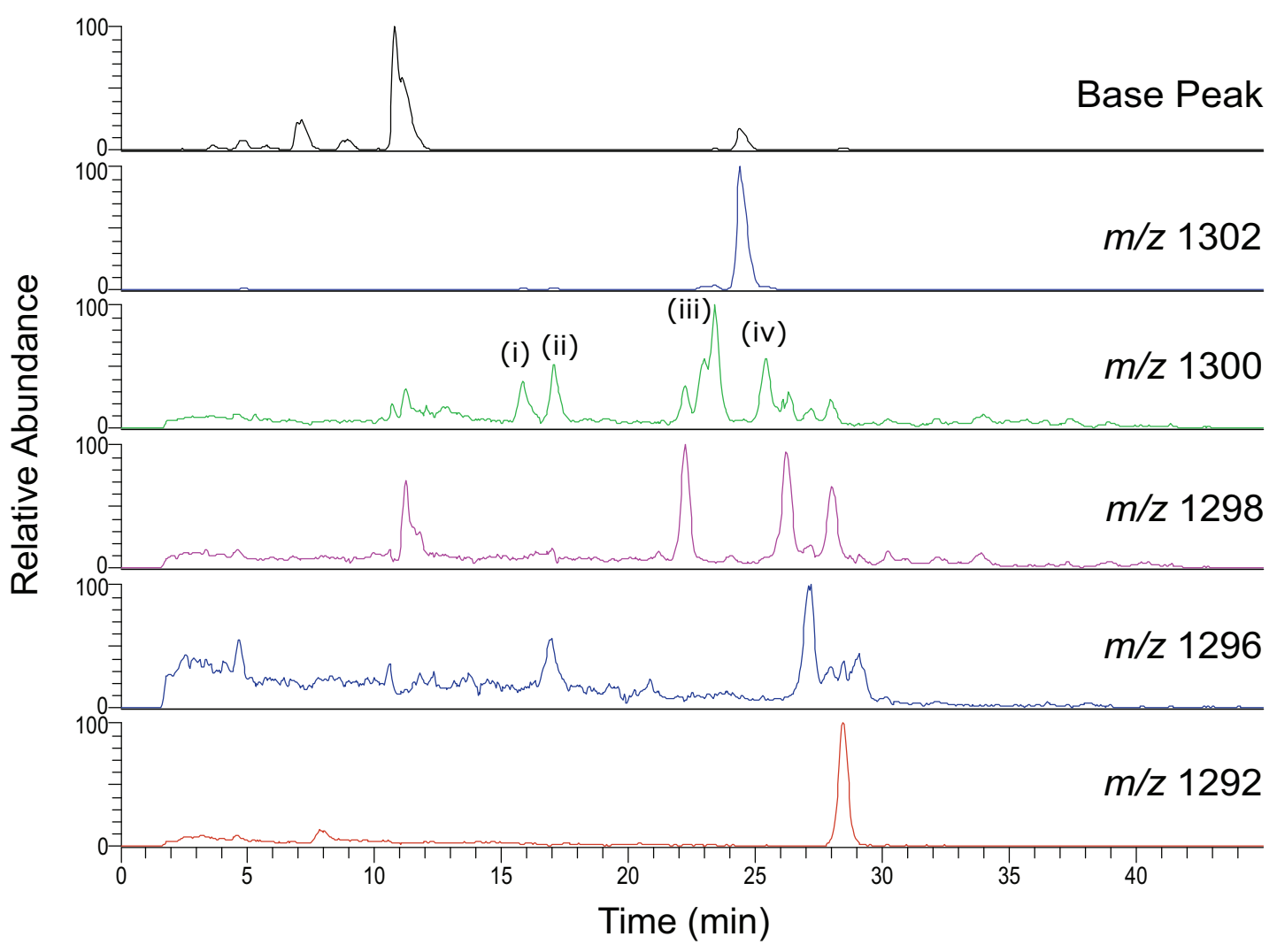

FIGURE 5 | HPLC-MS Single lon Monitoring chromatograms from a C18-XB analysis of the Swedish peat bog extract, showing multiple isoGDGT isomers.

as sharp peaks which create, in some cases, near baseline separation of a range of isomers. Based on the good isomer separation and the added advantage that it can be used for UHPLC applications, the C18-XB column was selected for further testing.

\section{GDGT and Isomer Separation Isoprenoid GDGTs in Marine Sediment}

To identify the GDGT structures on the C18-XB chromatogram, we fractionated a large quantity of the Baltic Sea total lipid extract using semi-preparative RP chromatography and (re-)injected the total extract (Figure 4A) and two fractions (18-21 $\mathrm{min}$ and 25-29 $\mathrm{min}$ ) on the NP cyano column (Figures $4 \mathrm{~B}, \mathrm{C}$ ). The fraction of isoprenoid GDGTs in group 1 on the C18-XB column (eluting 18-20 min) elute later, between 35 and $40 \mathrm{~min}$, when re-injected on the NP column (Figure 4B). The retention of the RP 18-20 min fraction in NP suggests that the $\mathrm{m} / z 1300, \mathrm{~m} / z$ $1298, \mathrm{~m} / z 1296$ are OH-GDGTs (Liu et al., 2012a), however, the inclusion of $\mathrm{m} / z 1302$ in the series and the placement of the $\mathrm{m} / z 1292$ isomer at $13 \mathrm{~min}$ suggests that these are a mix of OH-GDGTs with stereoisomers or isotopologs of the "regular isoGDGTs" (Figure 4B). Comparing the C18-XB elution pattern of the marine sediment isoGDGTs with published GDGT-RP methods (Zhu et al., 2013; Liu et al., 2019) also supports the earlier elution of $\mathrm{OH}-\mathrm{GDGTs}$ in comparison to the regular set of GDGTs. GDGT group 2 (25-29 min, C18-XB column) elute between 9 and 15 min on the NP column and are the "regular" isoGDGTs used to calculate the $\mathrm{TEX}_{86}$ proxy. The $\mathrm{m} / z 1292$ isomer is not present in the RP 25-29 min fractions as a typical NP shoulder peak where the regular $\mathrm{m} / z 1292$ elutes at $13 \mathrm{~min}$. Sinninghe Damsté et al. (2018) concluded that the 1292' isomer is in fact a stereo-isomer of the regular crenarchaeol where the cyclopentane ring next to the characteristic cyclohexane ring has a cis-configuration instead of the regular trans. This suggests that separation using the $\mathrm{C} 18-\mathrm{XB}$ method is sensitive to structural and stereo-isomeric differences of the biphytanyl chains of the GDGTs, on top of polarity. It also indicates that early eluting (group 2) GDGTs could be stereo-isomers of the regular trans isomers. Further work is needed to resolve the exact nature of the early eluting GDGTs on our RP method, although it is clear that the $m / z 1292^{\prime}$ crenarchaeol isomer used in the $\mathrm{TEX}_{86}$ elutes at the end of this group. An extracted ion chromatogram overview of isoprenoid and brGDGT isomers both identified and tentatively identified (based on comparison with other RP methods (Zhu et al., 2013; Liu et al., 2019), from the Baltic Sea extract is shown in Figure 4D.

\section{Isoprenoid GDGTs in a Peat Bog Lipid Extract}

Unusual separation of isoGDGTs was found when analyzing the Swedish peat bog extract using the C18-XB column. Multiple isomers were observed, especially for $m / z 1300,1298,1296$ 


\section{A Swedish peat bog extract HPLC fractionation}

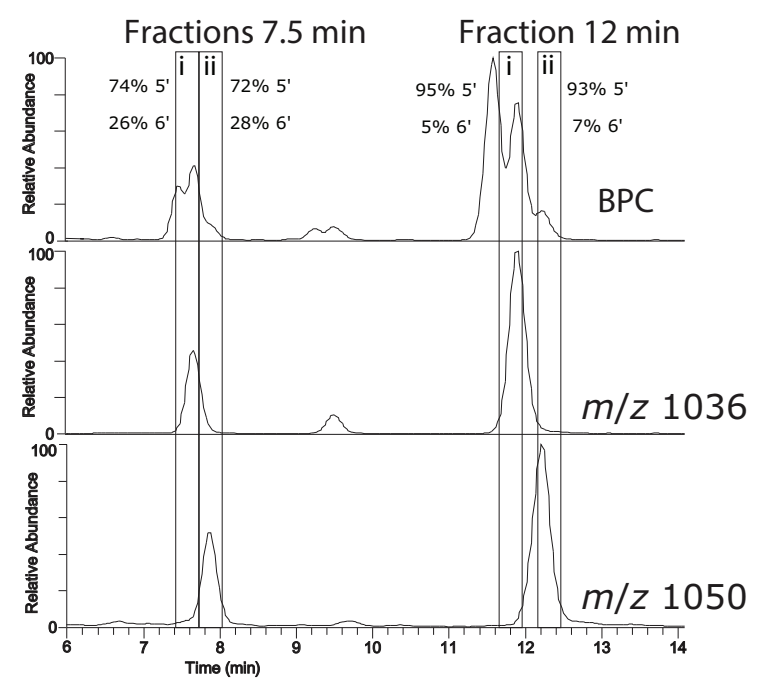

B Swedish peat bog GC/MS total ion chromatograms
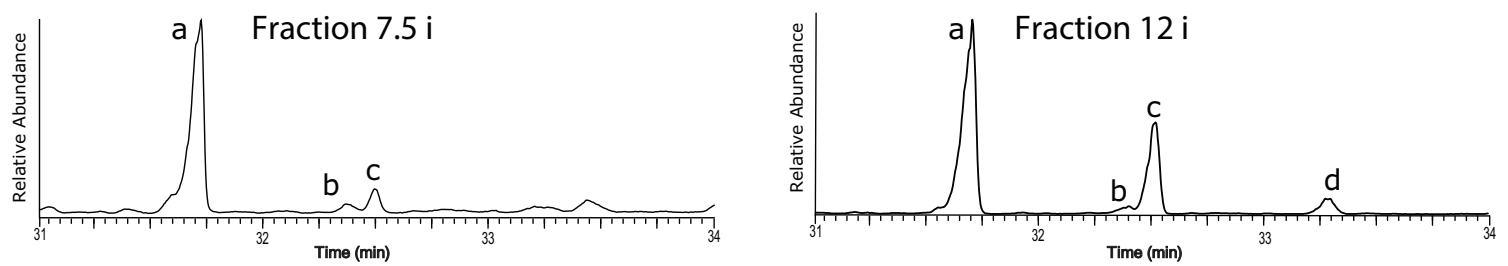

\section{c GC/MS spectra HPLC fraction $12 \mathrm{i}$}
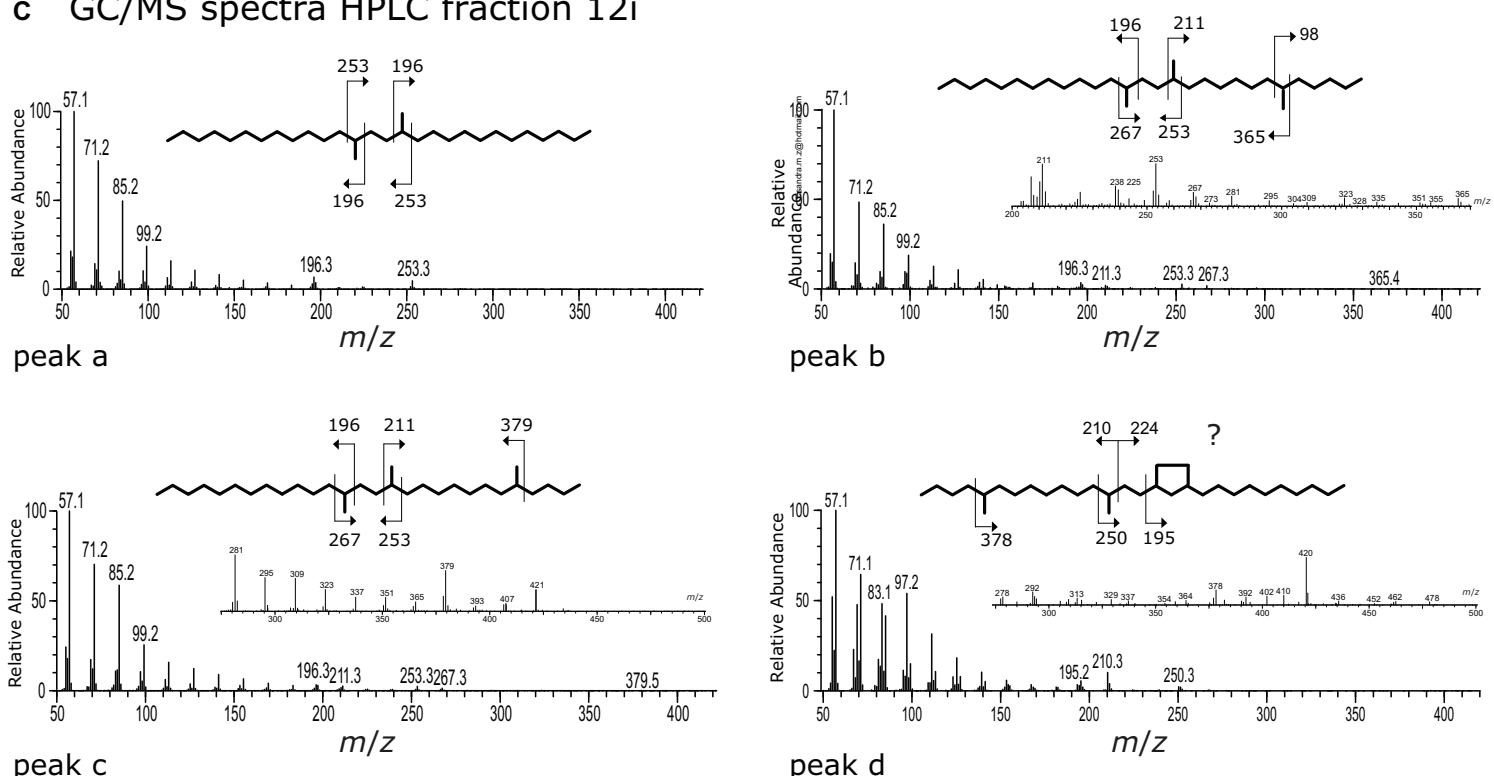

FIGURE 6 | (A) Partial base peak and m/z 1036 and m/z 1050 chromatograms from a Swedish Bog extract used for RP HPLC fraction collection. Boxes around 7.5 and 12 min show collection time windows where an earlier (i) and later (ii) fraction was taken at each collection time window. Fractions were subsequently ether cleaved and hydrogenated to elucidate the position ( $5^{\prime}$ or $\left.6^{\prime}\right)$ of the methyl group on the isomers. (B) GC-MS total ion chromatogram (TIC) from ether cleaved and hydrogenated HPLC fractions 7.5(i) and 12(i) from the Swedish peat bog. (C) GC-MS mass spectra from hydrocarbons a-d afforded from fraction 12(i) after ether cleavage and hydrogenation. 

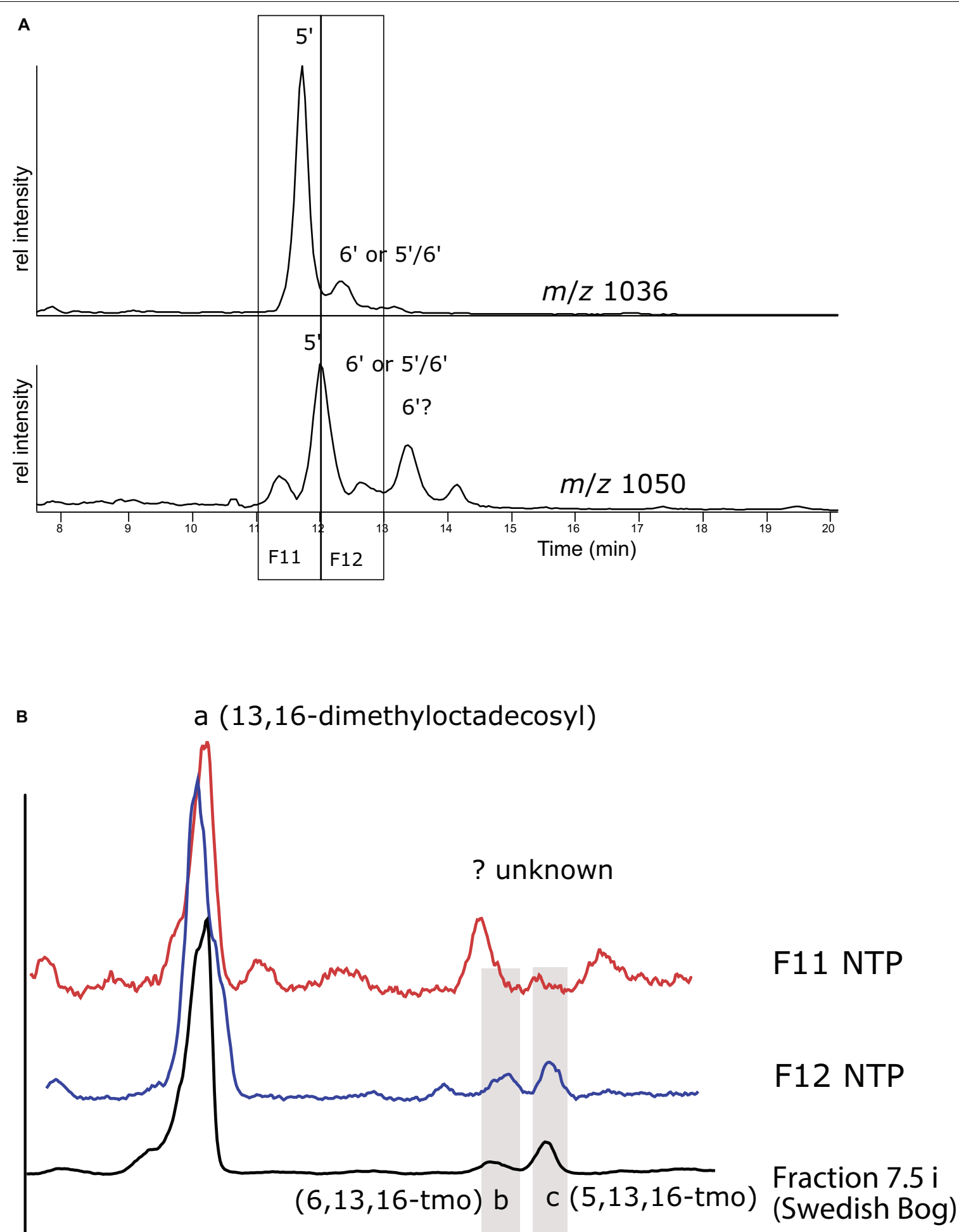

\section{Time}

FIGURE 7 | (A) Reverse phase HPLC-MS ion chromatograms showing the distribution of $\mathrm{m} / \mathrm{z} 1036 \mathrm{and} \mathrm{m} / \mathrm{z} 1050$ isomers in the NTP lake sediment extract. Numbers indicate the likely position of the methyl group on the isomers. (B) GC-MS total ion chromatogram (TIC) from ether cleaved and hydrogenated HPLC

fractions eluting between 11-12 and 12-13 min, compared with the TIC of the 7.5 min fraction from the Swedish peat bog (cf. Figure 6). The positions of 5,13,16 (b)- and 6,13,16-trimethyloctasanyl as identified in Figure 6 are indicated. 


\section{Taum Pyauk sediment extract}

Reverse Phase C18-XB

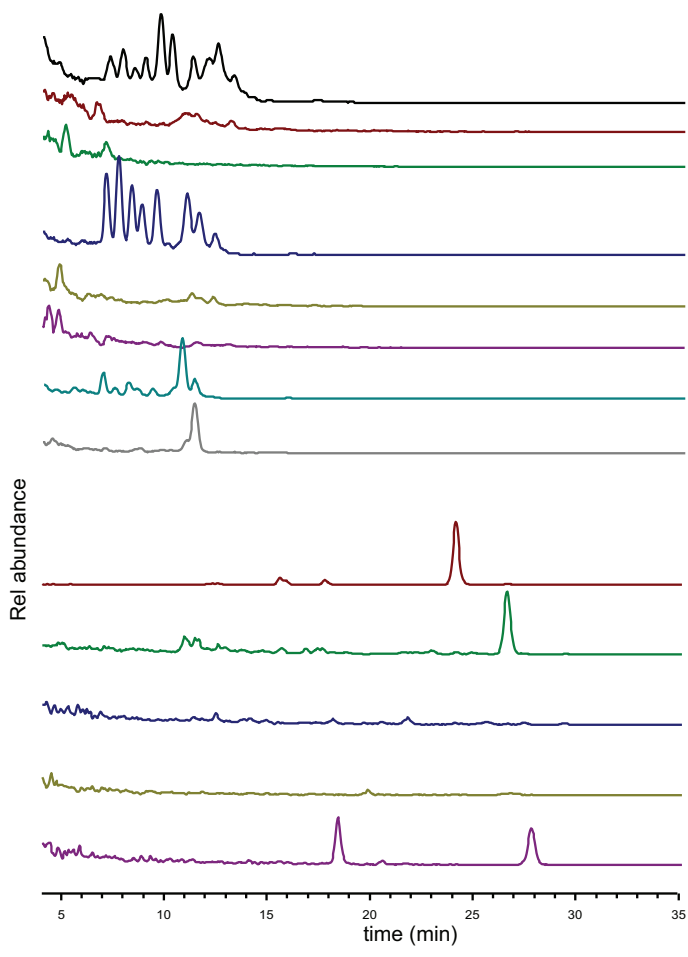

NP HILIC
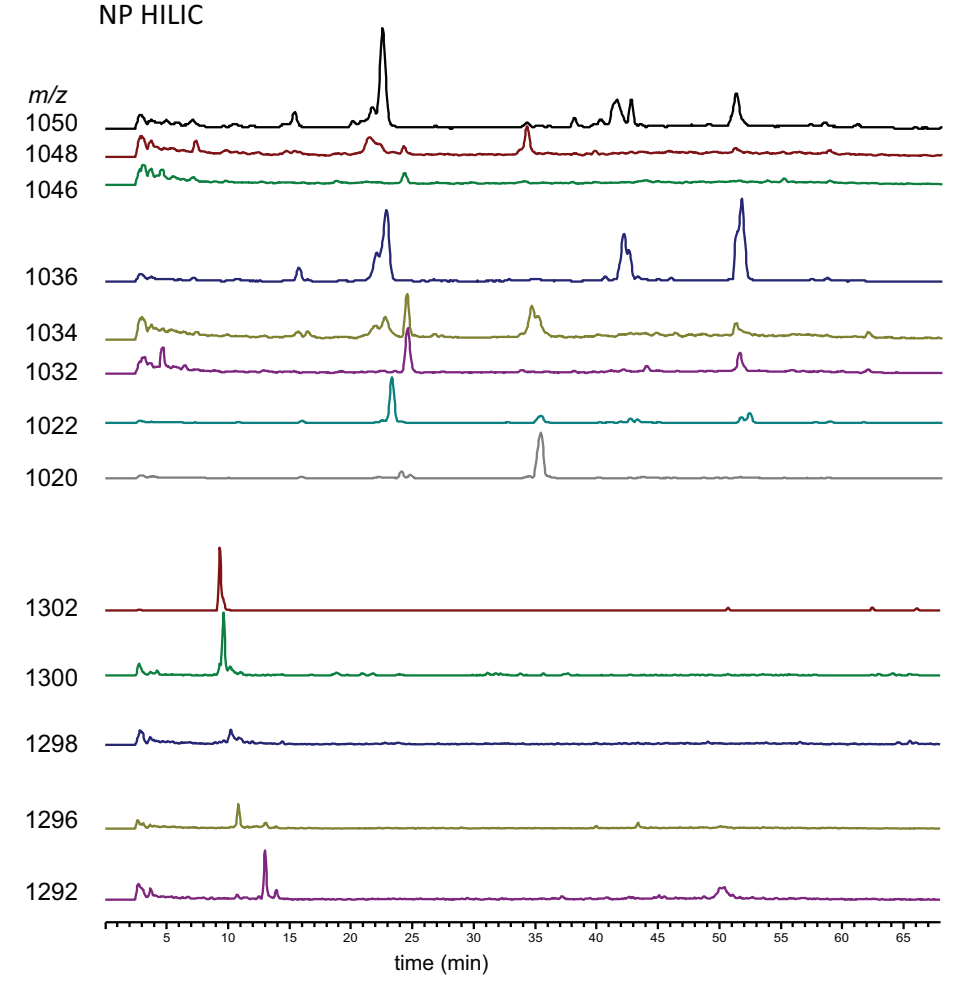

FIGURE 8 | C18-XB (left) and HILIC (right) selected ion chromatograms of branched and isoprenoid GDGTs from Taum Pyauk soda lake, Myanmar. In RP, many isomers can be observed for the branched GDGTs, while these are not clearly visible in NP. The $\mathrm{m} / \mathrm{z} 1292$ trace shows a clear isomer after the main peak at 13 min in the HILIC run. In RP, m/z 1292 exhibits two clear, nearly equally sized peaks.

(Figure 5 and Supplementary Figure S2). The same group 2 observed for the marine sample described above (eluting 25-29 $\mathrm{min}$ ) corresponds to the regular set of GDGTs. The crenarchaeol isomer $\mathrm{m} / z 1292^{\prime}$ (observed at $19 \mathrm{~min}$ in the marine sample), was not detected in the peat bog sample but the lack of crenarchaeol and its isomer has often been observed in peat samples (Schouten et al., 2000; Pancost and Sinninghe Damste, 2003; Weijers et al., 2004; Huguet et al., 2010; Zheng et al., 2015) and is attributed to the low abundance of ammonia-oxidizing Thaumarchaeota. A number of peaks of $\mathrm{m} / z 1300$ and $\mathrm{m} / z$ 1298 were observed between 10 and $24 \mathrm{~min}$. Our results show a similar pattern as those observed by Liu et al. (2016) using a different C18 RP method, who identified series of GDGTs with double bonds, cyclopentyl rings, and cyclohexyl rings ("SGDGTs") for $m / z 1300,1298$, and 1296, where more unsaturated bonds generally lead to shorter retention times and cyclohexyl rings to longer ones (Zhu et al., 2014); for structures see Liu et al. (2016). MS/MS fragmentation experiments on the $m / z 1300$ GDGT isomers at 15.8, 17.1, 23.4, $25.4 \mathrm{~min}$ (Supplementary Figure S2) all showed the typical fragmentation of the intact core GDGT and the product ion $(\mathrm{m} / z$ 743) formed from the loss of the 1,31-biphytadiene from the main molecule (Knappy et al., 2009). However, fragments $<m / z 743$ in spectra (i-iv) display varied fragmentation patterns, which are suspected to be caused by the structural differences of the various biphytane units within the $m / z 1300$ GDGT family. Our methods did not allow for further elucidation of the various GDGT structures, which requires the use of standards as well as ether cleavage experiments and subsequent analysis of the products by GC-MS. Isomers likely include unsaturated, hydroxyl and ring containing GDGTs as well as stereo-isomers but this needs to be experimentally verified. Liu et al. (2016) investigated the differences of NP and RP GDGT separation in detail. The NP double column method (Becker et al., 2013; Hopmans et al., 2016) gave improved separation of the GDGT isomers in comparison to the RP single column method (Zhu et al., 2013). While the isomers were less resolved using the RP method, an abundance of unusual GDGT isomers were identified, including variants containing unsaturated, cyclopentyl and cyclohexyl moieties.

\section{Branched GDGTs}

In order to attempt to identify the position of the brGDGT isomers eluted during the C18-XB method (Figure 3) we extracted a large quantity of Swedish bog material and subjected it to fraction collection using a semi-preparative C18-XB column, focusing on the pentamethylated $(\mathrm{m} / \mathrm{z} 1036$, IIa) and hexamethylated $(\mathrm{m} / z$ 1050, IIIa) GDGTs, which were most dominant (Figure 6). Interestingly there were two different sets with retention times at 7.5 and $12 \mathrm{~min}$ (Figure 6A). The two sets were collected and at each instance first a fraction 


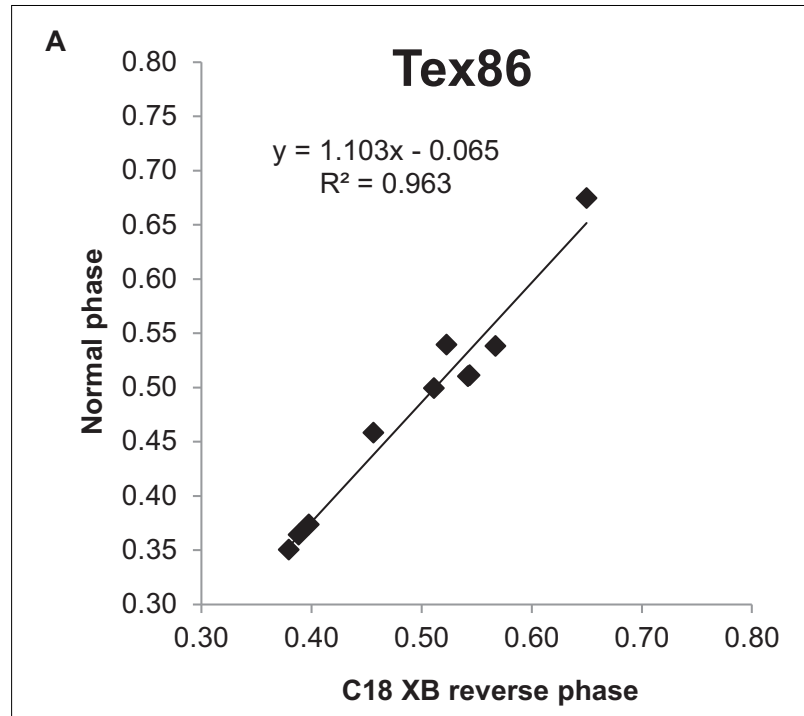

B

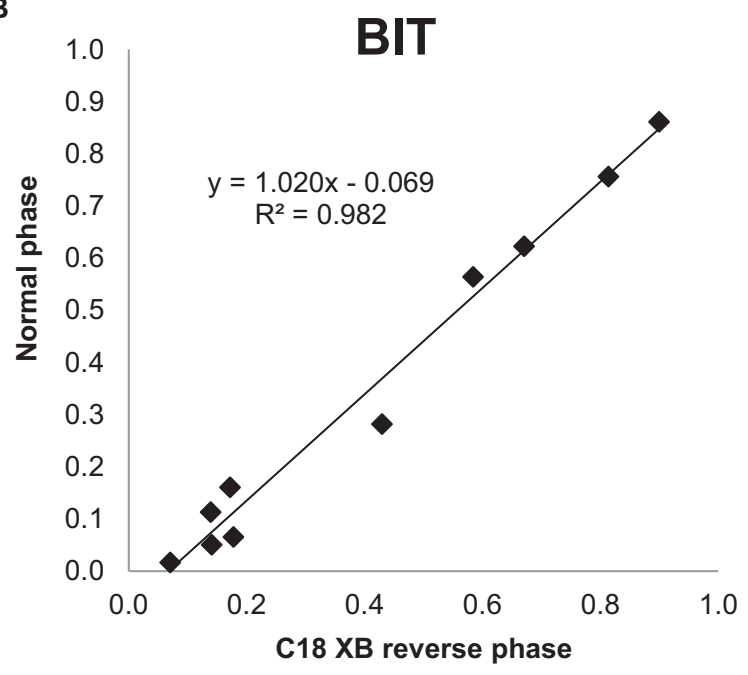

FIGURE 9 | Comparison of (A) BIT and (B) TEX 86 values obtained by Normal Phase (Cyano column) and Reverse Phase (C18-XB) chromatography.

containing predominantly IIa (labeled i) and then a fraction with mainly IIIa (labeled ii). Collected fractions were subjected to ether cleavage and hydrogenation, and individual fractions were analyzed by GC/MS. Figure 6B shows the partial GC/MS total ion chromatograms of the (i)-fractions collected at 7.5 and $12 \mathrm{~min}$; Figure 6C(a-d) and Supplementary Figures S3, S4 show mass spectra. We compared hydrocarbons $\mathrm{a}, \mathrm{b}, \mathrm{c}$ and $\mathrm{d}$ to previously reported chromatographic retention times and mass spectra (De Jonge et al., 2013; Ding et al., 2016). The relative amounts of 5,13,16- and 6,13,16-trimethyloctacosanyl (5-tmo and 6-tmo, respectively) analyzed using GC/MS can be used to back-calculate the relative abundance $5^{\prime}$ and $6^{\prime}$ isomers of IIa and IIIa within the collected fractions. The mass spectrum of
GC/MS peak b contains the pair $m / z$ 98/365 deriving from 6tmo, while $\mathrm{m} / \mathrm{z} 379$ indicates 5 -tmo for peak c. Peak d shows the characteristic fragments $m / z 210,250$ and 195 indicative the ringed structures observed by Ding et al. (2016), where $m / z 378$ indicates that this would be a 5-methyl isomer. However, the series of $m / z 83 / 97 / 101$ instead of the regular 85/99/103 does not agree with earlier published spectra. Concentrations were too low to further investigate the exact structure of peak d. In both the 7.5 and 12 min group there is one major isomer peak for IIa which, unlike the IIIa, has no small peaks or shoulders eluting prior to or after the main peak. Fractions i and ii eluting around $12 \mathrm{~min}$ had a higher percentage of 5-tmo (95\% and 93\%) than earlier eluting fractions at $7.5 \mathrm{~min}(74 \%, 72 \%)$. For both collection time windows the initial fraction (i) contained slightly more of the 5-methyl isomer than the subsequent fraction (ii). The ratio of 5 -tmo to 6 -tmo of IIa at 7.5 min suggests a mixed signal of $5^{\prime}, 5^{\prime} / 6^{\prime}$ and/or $6^{\prime}$ isomers (i.e., $\mathrm{IIa}_{5}, \mathrm{IIa}_{5 / 6}, \mathrm{II}_{6}$ ) and thus that these isomers are not well separated. Given the large percentage of the 5-tmo in the $12 \mathrm{~min}$ fractions, we infer that the here mainly 5-methyl isomers elute, however still with a small admixture of $6^{\prime}$ or $5^{\prime} / 6^{\prime}$ isomers. The question why there are two sets of isomers remains unresolved. Possibly, the earlier eluting set are $\mathrm{OH}$-brGDGT isomers; future analysis using an ESI source could provide evidence for this.

To verify our experimental procedure and to attempt to get more evidence for the elution order of the $5^{\prime}$ and $6^{\prime}$ isomers, HPLC fractions were collected, ether cleaved and hydrogenated from sediments of a tropical lake NTP, southern Thailand. Because of the tropical temperatures, the brGDGT distribution was dominated by the tetramethylated GDGTs (I), while the hexamethylated GDGTs (III) comprised less than $10 \%$. In the base peak chromatogram of the NTP extract IIIa isomers (1050) elute as five near-baseline separated peaks and there are at least two isomers of II (Figure 7A). Unfortunately, low recovery of material from the fraction collection experiment gave unsatisfying results but we could still draw some conclusions, also by comparing retention times with those from the peat bog analysis (Figure 7B). The fraction collected between 11 and 12 min was dominated by 13,16-dimethyloctadecosyl deriving from I and II. We tentatively assigned one peak to 5,13,16tmo but 6,13,16-tmo was not detected. Instead we observed another hydrocarbon that likely derived from a variety of I, but this remains speculation as the mass spectra were inconclusive (Supplementary Figure S5). The fraction eluting at $12-13$ min resulted in peaks both of 5,13,16- and 6,13,16tmo, the former around twice as large as the latter. This suggests that the largest peak of III (1050) is the $5^{\prime}$ isomer, while the subsequent peak could be the $6^{\prime}$ isomer or even the mixed 5/6 isomer, followed again by the $6^{\prime}$ isomer, in the same order as seen during the HILIC/NP separation (De Jonge et al., 2014a; Ding et al., 2016; Hopmans et al., 2016). For this sample, we clearly show that $\mathrm{C} 18-\mathrm{XB}$ method is capable of separating various structural isomers of the brGDGTs. The laborious method of identifying the exact structures of the alkyl groups complicates identification. Moreover, one needs to count on the possibility of asymmetric brGDGTs, i.e., combinations of di/tetra-methylated octacosanyl chains 

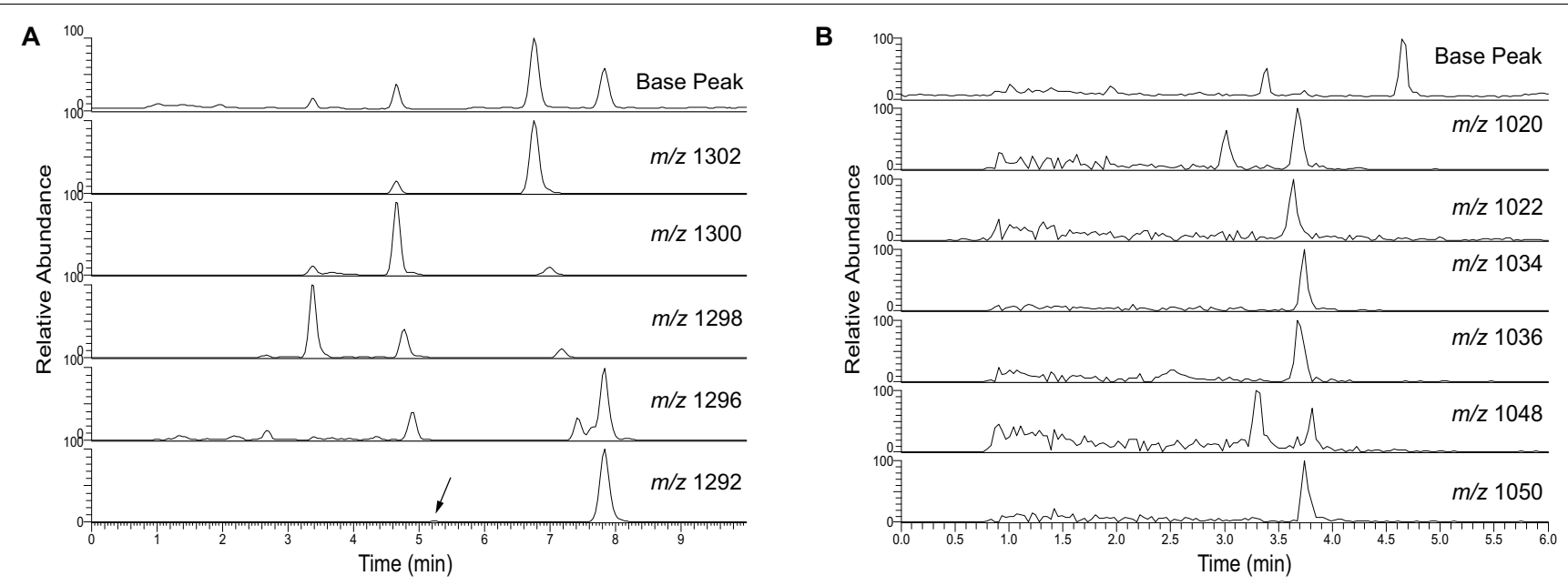

FIGURE 10 | UHPLC analyses of Baltic Sea surface sediment extract showing the base peak chromatogram of (A) isoprenoid GDGTs and (B) branched GDGTs. The arrow indicates the crenarchaeol isomer.

within the GDGT structures, and the potential for mixed 5/6, $5 / 7,6 / 7$ isomers.

As a last test to explore the differences between the RP C18-XB and the NP methods, we analyzed GDGTs extracted from sediment recovered from a soda lake (with a water $\mathrm{pH}$ of ca. 10) in Myanmar, using both the HILIC and the C18$\mathrm{XB}$ methods (Figure 8). Of note here is that the NP HILIC analysis was performed 2 years after the $\mathrm{C} 18$ - $\mathrm{XB}$ method; the GDGT fractions were stored at $-18^{\circ} \mathrm{C}$. Also, this sample comes from an extreme environment with reducing (euxinic) conditions at very high $\mathrm{pH}$. With the $\mathrm{C} 18$ - $\mathrm{XB}$ method we found a large suite of brGDGT isomers of especially Ia, IIa and IIIa, eluting between 7 and $14 \mathrm{~min}$, while the NP HILIC method gave some peaks at the "normal" retention time, but also several late eluting peaks. This suggests some of the early eluting brGDGTs (on RP) might be OH-GDGTs, which would elute late with HILIC/NP chromatography. We did not further pursue identification the compounds in this sample.

To conclude, the $\mathrm{C} 18-\mathrm{XB}$ method appears capable of separating a large range of brGDGT isomers, including $5^{\prime}$ and $6^{\prime}$ methyl isomers, although further work is needed to come to conclusive evidence of the exact order or chromatographic separation. Our results clearly indicate that the mixtures of brGDGTs in various settings are highly variable and of different complexity. The RP method presented here provides an additional tool to investigate the family of brGDGTs, a task that clearly is not finished yet.

\section{The Impact of the RP Method on the Calculation of the TEX ${ }_{86}$ and BIT Proxies}

$\mathrm{TEX}_{86}$ values of multiple environmental samples run on both the C18-XB and the Cyano column compared well $\left(r^{2}=0.96\right.$, $n=11$, Figure 9A). BIT indices measured on a small suite of environmental samples both using RP and NP methods also compared well $\left(r^{2}=0.98, n=10\right.$, Figure 9B). Despite tentative assignment of 5-methyl GDGTs, we refrain from discussing the $\mathrm{MBT}_{(5 \mathrm{Me})}$ and $\mathrm{CBT}_{(5 \mathrm{Me})}$ proxies as we could not always account for all isomers when comparing our results with the HILIC method. More sample comparisons are needed to further substantiate the transferability of the GDGT-based proxy results between the different methods. However, we argue that final results of any study using GDGT proxies will likely depend more on the choice of calibration, and the extent to which that calibration is evaluated and validated for a particular site or setting, than on the chromatographic method used.

\section{Adaption to UPLC}

UHPLC ( $>600$ bar) has the advantages of fast run times and low injection volume, in this case $2 \mu$, which is essential for creating sharp peaks to improve baseline resolution (Figure 10). The run time of the UHPLC method is ultimately limited by the tailing hump of unresolved compounds which is eluting soon after injection. The isoprenoid and brGDGTs elute within $10 \mathrm{~min}$ and the total run time is $15 \mathrm{~min}$ including column flushing. Comparing Figure 10 with Figures 3, 4 shows that GDGT peak distribution remains the same in the UHPLC and RP 45 min run. The $\mathrm{TEX}_{86}$ values calculated for a Black Sea surface sediment after analysis using the NP, RP HPLC, and RP UHPLC methods gave the same results (Supplementary Table S4), and corresponded also with the value published by Wakeham et al. (2003). BIT values were also comparable for the three methods (Supplementary Table S4) when applied to Extract $\mathrm{E}$ from the $\mathrm{TEX}_{86}$ and BIT intercalibration study performed by Schouten et al. (2013a). Tentative assignment of the various brGDGTs and subsequent calculation of $\mathrm{MBT}_{5 \mathrm{Me}}^{\prime}, \mathrm{CBT}_{5 \mathrm{Me}}$ and $\mathrm{CBT}^{\prime}$ proxies gave identical results when comparing the 45 min RP method (see Supplementary Figure S7 for the HPLC chromatogram) with the 15 min UHPLC method (Supplementary Table S4). These initial tests suggest a good agreement of the different proxy calculations indicating that both the RP HPLC and 
UHPLC methods provide proxy calculation comparable to the original NP method.

\section{CONCLUSION}

The chromatography of four different core-shell polymer phases on the elution of isoprenoidal and brGDGT isomers has been investigated. The $\mathrm{C} 18-\mathrm{XB}$ column was ultimately chosen based on good peak elution, acceptable runtime and the capability to run under UHPLC conditions. The C18-XB column separated isoGDGTs into two groups. The first group consisting of OH-GDGTs appears to contain admixtures of structural isomers of the "normal" isoGDGTs, which predominantly elute in group 2. Surprisingly, the crenarchaeol isomer used in the $\mathrm{TEX}_{86}$ proxy eluted at the end of the first group. BrGDGTs elute before the isoGDGTs, which makes the RP chromatography more time efficient for these compounds compared to the regularly used NP methods. Besides a swapped elution order based on mass (i.e., the compound with $\mathrm{m} / \mathrm{z} 1050$ elutes before the $\mathrm{m} / \mathrm{z} 1036$ compound and before the $\mathrm{m} / z 1022$ compound) compared to NP chromatography (where compounds elute in the order $\mathrm{m} / z$ 1022, $\mathrm{m} / z$ 1036, $m / z$ 1050), the RP method appears to separate the various structural isomers with different methyl-group positioning on the octacosanyl chains in the same way as NP (i.e., 5-methyl brGDGTs elute before 6-methyl brGDGTs). However, we did not manage to arrive at unequivocal evidence for the exact positioning of these isomers. Moreover, in some samples we found a larger variety of apparent isomers than observed in the regular analytical window of NP chromatography, while in others we found less. Comparison of a limited set of samples run both on the RP method using the C18$\mathrm{XB}$ column, and the traditionally used NP method using a Cyano column, gave virtually the same BIT index values and highly similar $\mathrm{TEX}_{86}$ values. Besides being a possible alternative to the existing NP methods, the unusual isoprenoid and brGDGT isomer separation on the C18-XB column could aid further elucidation of the biological sources and environmental factors that play a role in the production of the different GDGT isomers.

\section{REFERENCES}

Becker, K. W., Lipp, J. S., Zhu, C., Liu, X. L., and Hinrichs, K. U. (2013). An improved method for the analysis of archaeal and bacterial ether core lipids. Org. Geochem. 61, 34-44. doi: 10.1016/j.orggeochem.2013.05.007

Birkholz, A., Smittenberg, R. H., Hajdas, I., Wacker, L., and Bernasconi, S. M. (2013). Isolation and compound specific radiocarbon dating of terrigenous branched glycerol dialkyl glycerol tetraethers (brGDGTs). Org. Geochem. 60, 9-19. doi: 10.1016/j.orggeochem.2013.04.008

Brochier-Armanet, C., Gribaldo, S., and Forterre, P. (2012). Spotlight on the Thaumarchaeota. ISME J. 6, 227-230. doi: 10.1038/ismej.2011.145

De Jonge, C., Hopmans, E. C., Stadnitskaia, A., Rijpstra, W. I. C., Hofland, R., Tegelaar, E., et al. (2013). Identification of novel penta- and hexamethylated branched glycerol dialkyl glycerol tetraethers in peat using HPLC-MS2, GC-MS and GC-SMB-MS. Org. Geochem. 54, 78-82. doi: 10.1016/j.orggeochem.2012. 10.004

\section{DATA AVAILABILITY STATEMENT}

The datasets generated for this study are available on request to the corresponding authors.

\section{AUTHOR CONTRIBUTIONS}

Both authors carried out analytical work and performed data analysis, interpretation, and manuscript writing.

\section{FUNDING}

The research was funded by a start-up grant from the Bolin Centre for Climate Research, Stockholm University (JR) and the Swedish Research Council grant 621-2011-4916 (RS). This article is published as a contribution to the proceedings of the Marine Organic Geochemistry Workshop held in April 2019 in Delmenhorst, funded by the Deutsche Forschungsgemeinschaft (DFG, German Research Foundation) project number 422798570. In addition, the Hanse-Wissenschaftskolleg and the Geochemical Society provided funding for the conference.

\section{ACKNOWLEDGMENTS}

We would like to thank Enrique Iñiguez, Kweku Yamoah, and Alan Wiech for laboratory assistance and data analysis. Francesco Muschitiello and Joanna Sawicka provided samples. Mandana Fasth and Sven Josefsson from Phenomenex Sweden provided advice on column selection and chromatography. Three reviewers greatly helped improve an earlier version of this manuscript.

\section{SUPPLEMENTARY MATERIAL}

The Supplementary Material for this article can be found online at: https://www.frontiersin.org/articles/10.3389/fmars. 2020.539601/full\#supplementary-material

De Jonge, C., Hopmans, E. C., Zell, C. I., Kim, J. H., Schouten, S., and Sinninghe Damsté, J. S. (2014a). Occurrence and abundance of 6-methyl branched glycerol dialkyl glycerol tetraethers in soils: implications for palaeoclimate reconstruction. Geochim. Cosmochim. Acta 141, 97-112. doi: 10.1016/j.gca. 2014.06.013

De Jonge, C., Stadnitskaia, A., Hopmans, E. C., Cherkashov, G., Fedotov, A., and Sinninghe Damsté, J. S. (2014b). In situ produced branched glycerol dialkyl glycerol tetraethers in suspended particulate matter from the Yenisei River, Eastern Siberia. Geochim. Cosmochim. Acta 125, 476-491. doi: 10.1016/j.gca. 2013.10.031

de la Torre, J. R., Walker, C. B., Ingalls, A. E., Könneke, M., and Stahl, D. A. (2008). Cultivation of a thermophilic ammonia oxidizing archaeon synthesizing crenarchaeol. Environ. Microbiol. 10, 810-818. doi: 10.1111/j.1462-2920.2007. 01506.x

Ding, S., Schwab, V. F., Ueberschaar, N., Roth, V.-N., Lange, M., Xu, Y., et al. (2016). Identification of novel 7-methyl and cyclopentanyl branched glycerol 
dialkyl glycerol tetraethers in lake sediments. Org. Geochem. 102, 52-58. doi: 10.1016/j.orggeochem.2016.09.009

Elling, F. J., Könneke, M., Nicol, G. W., Stieglmeier, M., Bayer, B., Spieck, E., et al. (2017). Chemotaxonomic characterisation of the thaumarchaeal lipidome. Environ. Microbiol. 19, 2681-2700. doi: 10.1111/1462-2920.13759

Graeve, M., and Janssen, D. (2009). Improved separation and quantification of neutral and polar lipid classes by HPLC-ELSD using a monolithic silica phase: application to exceptional marine lipids. J. Chromatogr. B Anal. Technol. Biomed. Life Sci. 877, 1815-1819. doi: 10.1016/j.jchromb.2009.05.004

Hopmans, E. C., Schouten, S., and Sinninghe Damsté, J. S. (2016). The effect of improved chromatography on GDGT-based paleoproxies. Org. Geochem. 93, 1-6. doi: 10.1016/j.orggeochem.2015.12.006

Hopmans, E. C., Weijers, J. W. H., Schefuss, E., Herfort, L., Sinninghe Damsté, J. S., and Schouten, S. (2004). A novel proxy for terrestrial organic matter in sediments based on branched and isoprenoid tetraether lipids. Earth Planet. Sci. Lett. 224, 107-116. doi: 10.1016/j.epsl.2004.05.012

Huguet, A., Fosse, C., Laggoun-Defarge, F., Toussaint, M. L., and Derenne, S. (2010). Occurrence and distribution of glycerol dialkyl glycerol tetraethers in a French peat bog. Org. Geochem. 41, 559-572. doi: 10.1016/j.orggeochem.2010. 02.015

Kim, J. H., Schouten, S., Hopmans, E. C., Donner, B., and Sinninghe Damsté, J. S. (2008). Global sediment core-top calibration of the TEX86 paleothermometer in the ocean. Geochim. Cosmochim. Acta 72, 1154-1173. doi: 10.1016/j.gca. 2007.12.010

Knappy, C. S., Chong, J. P. J., and Keely, B. J. (2009). Rapid discrimination of archaeal tetraether lipid cores by liquid chromatography-tandem mass spectrometry. J. Am. Soc. Mass Spectrom. 20, 51-59. doi: 10.1016/j.jasms.2008. 09.015

Könneke, M., Schubert, D. M., Brown, P. C., Hugler, M., Standfest, S., Schwander, T., et al. (2014). Ammonia-oxidizing archaea use the most energy-efficient aerobic pathway for CO2 fixation. Proc. Natl. Acad.Sci. U.S.A. 111, 8239-8244. doi: 10.1073/pnas.1402028111

Kuypers, M. M. M., Blokker, P., Erbacher, J., Kinkel, H., Pancost, R. D., Schouten, S., et al. (2001). Massive expansion of marine archaea during a mid-Cretaceous oceanic anoxic event. Science 293, 92-94. doi: 10.1126/science.1058424

Lanekoff, I., and Karlsson, R. (2010). Analysis of intact ladderane phospholipids, originating from viable anammox bacteria, using RP-LC-ESI-MS. Anal. Bioanal. Chem. 397, 3543-3551. doi: 10.1007/s00216-010-3913-3

Liu, X. L., Lipp, J. S., Birgel, D., Summons, R. E., and Hinrichs, K. U. (2018). Predominance of parallel glycerol arrangement in archaeal tetraethers from marine sediments: structural features revealed from degradation products. Org. Geochem. 115, 12-23. doi: 10.1016/j.orggeochem.2017.09.009

Liu, X. L., Lipp, J. S., Simpson, J. H., Lin, Y. S., Summons, R. E., and Hinrichs, K. U. (2012a). Mono- and dihydroxyl glycerol dibiphytanyl glycerol tetraethers in marine sediments: identification of both core and intact polar lipid forms. Geochim. Cosmochim. Acta 89, 102-115. doi: 10.1016/j.gca.2012.04.053

Liu, X. L., Russell, D. A., Bonfio, C., and Summons, R. E. (2019). Glycerol configurations of environmental GDGTs investigated using a selective sn2 ether cleavage protocol. Org. Geochem. 128, 57-62. doi: 10.1016/j.orggeochem.2018. 12.003

Liu, X. L., Summons, R. E., and Hinrichs, K. U. (2012b). Extending the known range of glycerol ether lipids in the environment: structural assignments based on tandem mass spectral fragmentation patterns. Rapid Commun. Mass Spectrom. 26, 2295-2302. doi: 10.1002/rcm.6355

Liu, X. L., Torio, A. D., Bosak, T., and Summons, R. E. (2016). Novel archaeal tetraether lipids with a cyclohexyl ring identified in Fayetteville Green Lake, NY, and other sulfidic lacustrine settings. Rapid Commun. Mass Spectrom. 30, 1197-1205. doi: 10.1002/rcm.7549

Liu, X. L., Zhu, C., Wakeham, S. G., and Hinrichs, K. U. (2014). In situ production of branched glycerol dialkyl glycerol tetraethers in anoxic marine water columns. Mar. Chem. 166, 1-8. doi: 10.1016/j.marchem.2014.08.008

Naafs, B. D. A., Inglis, G. N., Zheng, Y., Amesbury, M. J., Biester, H., Bindler, R., et al. (2017). Introducing global peat-specific temperature and $\mathrm{pH}$ calibrations based on brGDGT bacterial lipids. Geochim. Cosmochim. Acta 208, 285-301. doi: 10.1016/j.gca.2017.01.038

Naafs, B. D. A., Mccormick, D., Inglis, G. N., Pancost, R. D., and Collaborators, T. G. P. D. (2018). Archaeal and bacterial H-GDGTs are abundant in peat and their relative abundance is positively correlated with temperature. Geochim. Cosmochim. Acta 227, 156-170. doi: 10.1016/j.gca.2018.02.025

Pancost, R. D., and Sinninghe Damste, J. S. (2003). Carbon isotopic compositions of prokaryotic lipids as tracers of carbon cycling in diverse settings. Chem. Geol. 195, 29-58. doi: 10.1016/s0009-2541(02)00387-x

Pearson, A., Huang, Z., Ingalls, A. E., Romanek, C. S., Wiegel, J., Freeman, K. H., et al. (2004). Nonmarine crenarchaeol in Nevada hot springs. Appl. Environ. Microbiol. 70, 5229-5237. doi: 10.1128/aem.70.9.5229-5237.2004

Robinson, S. A., Ruhl, M., Astley, D. L., Naafs, B. D. A., Farnsworth, A. J., Bown, P. R., et al. (2016). Early jurassic north Atlantic sea-surface temperatures from TEX86 palaeothermometry. Sedimentology 64:215. doi: 10.1111/sed.12321

Russell, J. M., Hopmans, E. C., Loomis, S. E., Liang, J., and Sinninghe Damsté, J. S. (2018). Distributions of 5-and 6-methyl branched glycerol dialkyl glycerol tetraethers (brGDGTs) in East African lake sediment: effects of temperature, $\mathrm{pH}$, and new lacustrine paleotemperature calibrations. Organ. Geochem.117, 56-69. doi: 10.1016/j.orggeochem.2017.12.003

Schoon, P. L., De Kluijver, A., Middelburg, J. J., Downing, J. A., Sinninghe Damsté, J. S., and Schouten, S. (2013). Influence of lake water $\mathrm{pH}$ and alkalinity on the distribution of core and intact polar branched glycerol dialkyl glycerol tetraethers (GDGTs) in lakes. Org. Geochem. 60, 72-82. doi: 10.1016/j. orggeochem.2013.04.015

Schouten, S., Hopmans, E. C., Pancost, R. D., and Sinninghe Damsté, J. S. (2000). Widespread occurrence of structurally diverse tetraether membrane lipids: evidence for the ubiquitous presence of low-temperature relatives of hyperthermophiles. Proc. Natl. Acad. Sci. U.S.A. 97, 14421-14426. doi: 10.1073/ pnas.97.26.14421

Schouten, S., Hopmans, E. C., Schefus, E., and Sinninghe Damsté, J. S. (2002). Distributional variations in marine crenarchaeotal membrane lipids: a new tool for reconstructing ancient sea water temperatures? Earth Planet. Sci. Lett. 204, 265-274. doi: 10.1016/s0012-821x(02)00979-2

Schouten, S., Van Der Meer, M. T. J., Hopmans, E. C., Rijpstra, W. I. C., Reysenbach, A. L., Ward, D. M., et al. (2007). Archaeal and bacterial glycerol dialkyl glycerol tetraether lipids in hot springs of yellowstone National Park. Appl. Environ. Microbiol. 73, 6181-6191. doi: 10.1128/aem.00630-07

Schouten, S., Hopmans, E. C., Rosell-Melé, A., Pearson, A., Adam, P., Bauersachs, T., et al. (2013a). An interlaboratory study of TEX86 and BIT analysis of sediments, extracts, and standard mixtures. Geochem. Geophys. Geosyst. 14, 5263-5285.

Schouten, S., Hopmans, E. C., and Sinninghe Damsté, J. S. (2013b). The organic geochemistry of glycerol dialkyl glycerol tetraether lipids: a review. Org. Geochem. 54, 19-61. doi: 10.1016/j.orggeochem.2012.09.006

Sinninghe Damsté, J. S., Rijpstra, W. I. C., Hopmans, E. C., Den Uijl, M. J., Weijers, J. W. H., and Schouten, S. (2018). The enigmatic structure of the crenarchaeol isomer. Org. Geochem. 124, 22-28. doi: 10.1016/j.orggeochem.2018.06.005

Tierney, J. E., Schouten, S., Pitcher, A., Hopmans, E. C., and Sinninghe Damsté, J. S. (2012). Core and intact polar glycerol dialkyl glycerol tetraethers (GDGTs) in Sand Pond, Warwick, Rhode Island (USA): insights into the origin of lacustrine GDGTs. Geochim. Cosmochim. Acta 77, 561-581. doi: 10.1016/j.gca.2011.10. 018

Tolar, B. B., Ross, M. J., Wallsgrove, N. J., Liu, Q., Aluwihare, L. I., Popp, B. N., et al. (2016). Contribution of ammonia oxidation to chemoautotrophy in Antarctic coastal waters. ISME J. 10, 2605-2619. doi: 10.1038/ismej.2016.61

Wakeham, S. G., Lewis, C. M., Hopmans, E. C., Schouten, S., and Sinninghe Damsté, J. S. (2003). Archaea mediate anaerobic oxidation of methane in deep euxinic waters of the Black Sea. Geochim. Cosmochim. Acta 67, 1359-1374. doi: 10.1016/s0016-7037(02)01220-6

Weber, Y., De Jonge, C., Rijpstra, W. I. C., Hopmans, E. C., Stadnitskaia,. A., Schubert, C. J., et al. (2015). Identification and carbon isotope composition of a novel branched GDGT isomer in lake sediments: evidence for lacustrine branched GDGT production. Geochim. Cosmochim. Acta 154, 118-129 doi: 10.1016/j.gca.2015.01.032

Weijers, J. W. H., Panoto, E., Van Bleijswijk, J., Schouten, S., Rijpstra, W. I. C., Balk, M., et al. (2009). Constraints on the biological source(s) of the orphan branched tetraether membrane lipids. Geomicrobiol. J. 26, 402-414. doi: 10. 1080/01490450902937293

Weijers, J. W. H., Schouten, S., Van Den Donker, J. C., Hopmans, E. C., and Sinninghe Damsté, J. S. (2007). Environmental controls on bacterial tetraether 
membrane lipid distribution in soils. Geochim. Cosmochim. Acta 71, 703-713. doi: 10.1016/j.gca.2006.10.003

Weijers, J. W. H., Schouten, S., Van Der Linden, M., Van Geel, B., and Sinninghe Damsté, J. S. (2004). Water table related variations in the abundance of intact archaeal membrane lipids in a Swedish peat bog. FEMS Microbiol. Lett. 239, 51-56. doi: 10.1016/j.femsle.2004.08.012

Wörmer, L., Lipp, J. S., Schröder, J. M., and Hinrichs, K. U. (2013). Application of two new LC-ESI-MS methods for improved detection of intact polar lipids (IPLs) in environmental samples. Organ. Geochem. 59, 10-21. doi: 10.1016/j. orggeochem.2013.03.004

Zhang, C. L., Pearson, A., Li, Y. L., Mills, G., and Wiegel, J. (2006). Thermophilic temperature optimum for crenarchaeol synthesis and its implication for archaeal evolution. Appl. Environ. Microbiol. 72, 4419-4422. doi: 10.1128/aem. 00191-06

Zhang, Y. G., Pagani, M., and Wang, Z. R. (2016). Ring Index: a new strategy to evaluate the integrity of TEX86 paleothermometry. Paleoceanography 31, 220-232. doi: 10.1002/2015pa002848

Zhang, Z. H., Smittenberg, R. H., and Bradley, R. S. (2016). GDGT distribution in a stratified lake and implications for the application of TEX86 in paleoenvironmental reconstructions. Sci. Rep. 6:10.

Zheng, Y. H., Li, Q. Y., Wang, Z. Z., Naafs, B. D. A., Yu, X. F., and Pancost, R. D. (2015). Peatland GDGT records of Holocene climatic and biogeochemical responses to the Asian Monsoon. Org. Geochem. 87, 86-95. doi: 10.1016/j. orggeochem.2015.07.012

Zhu, C., Lipp, J. S., Wörmer, L., Becker, K. W., Schröder, J., and Hinrichs, K. U. (2013). Comprehensive glycerol ether lipid fingerprints through a novel reversed phase liquid chromatography-mass spectrometry protocol. Org. Geochem. 65, 53-62. doi: 10.1016/j.orggeochem.2013.09. 012

Zhu, C., Yoshinaga, M. Y., Peters, C. A., Liu, X. L., Elvert, M., and Hinrichs, K. U. (2014). Identification and significance of unsaturated archaeal tetraether lipids in marine sediments. Rapid Commun. Mass Spectrom. 28, 1144-1152. doi: $10.1002 / \mathrm{rcm} .6887$

Conflict of Interest: The authors declare that the research was conducted in the absence of any commercial or financial relationships that could be construed as a potential conflict of interest.

Copyright $(52020$ Rattray and Smittenberg. This is an open-access article distributed under the terms of the Creative Commons Attribution License (CC BY). The use, distribution or reproduction in other forums is permitted, provided the original author(s) and the copyright owner(s) are credited and that the original publication in this journal is cited, in accordance with accepted academic practice. No use, distribution or reproduction is permitted which does not comply with these terms. 